\title{
LASER ADDITIVE MANUFACTURING OF MAGNETIC MATERIALS
}

Calvin Vijay Mikler

Thesis Prepared for the Degree of

MASTER OF SCIENCE

UNIVERSITY OF NORTH TEXAS

August 2017

APPROVED:

Rajarshi Banerjee, Major Professor

Thomas Scharf, Committee Member James Williams, Committee Member Andrey Voevodin, Chair of the Department of Materials Science and Engineering Costas Tsatsoulis, Dean of the College of Engineering

Victor Prybutok, Dean of the Toulouse Graduate School 


\section{Mikler, Calvin Vijay. Laser Additive Manufacturing of Magnetic Materials. Master of}

Science (Materials Science and Engineering), August 2017, 64 pp., 2 tables, 21 figures, chapter references.

A matrix of variably processed Fe-30at\% Ni was deposited with variations in laser travel speeds as well and laser powers. A complete shift in phase stability occurred as a function of varying laser travel speed. At slow travel speeds, the microstructure was dominated by a columnar fcc phase. Intermediate travel speeds yielded a mixed microstructure comprised of both the columnar $f c c$ and a martensite-like bcc phase. At the fastest travel speed, the microstructure was dominated by the bcc phase. This shift in phase stability subsequently affected the magnetic properties, specifically saturation magnetization. Ni-Fe-Mo and Ni-Fe-V permalloys were deposited from an elemental blend of powders as well. Both systems exhibited featureless microstructures dominated by an fcc phase. Magnetic measurements yielded saturation magnetizations on par with conventionally processed permalloys, however coercivities were significantly larger; this difference is attributed to microstructural defects that occur during the additive manufacturing process. Finally, a compositionally graded AlCox $\mathrm{Cr}_{1-\mathrm{x}} \mathrm{FeNi}(0.0<\mathrm{x}<1.0)$ complex concentrated alloy was deposited with six distinct compositional steps. As a function of composition, the microstructure varied from single phase B2 (ordered) to a mixture of B2 $+b c c$ (disordered). Increasing chromium content results in a spinodal decomposition within the matrix, forming a $\mathrm{B} 2+b c c$ microstructure. Saturation magnetizations are highest at $x=1.0$ (AlCoFeNi), and lowest at $x=0.0$ (AlCrFeNi). The coercivity reached a maximum at $\mathrm{x}=0.4$. 
Copyright 2017

by

Calvin Vijay Mikler 


\section{ACKNOWLEDGMENTS}

My sincerest gratitude to Dr. Rajarshi Banerjee, my advisor, for his guidance, his kindness, and coffee. A special thank-you also to my committee members: Dr. Tom Scharf and Dr. Jim Williams. I thank the faculty and staff of the Department of Materials Science \& Engineering at UNT for their help, advice, and support throughout my graduate and undergraduate career.

This research would not have been possible if not for the help of several key people in the Banerjee group: Dr. Tushar Borkar, Srinivas Mantri, Bharat Gwalani, Vishal Soni, Sheena Valentin, Dr. Talukder Alam, and Dr. Deep Choudhuri. It also would not have been possible without our collaborators at Nanyang Technological University in Singapore: Dr. Raju V. Ramanujan and Dr. Varun Chaudhary, for supplying us incredible amounts of support for magnetic properties analysis.

I would also extend my utmost thanks and appreciation to Christopher Yannetta, with whom I have worked extensively in my undergraduate and graduate career. A special thanks to Dr. Richard "Just call me Rick" Reidy for his guidance on a number of things, whether it be life, or some odd question that plagues the mind (e.g., what animal would win in a battle royal). I also thank Nathan Ley, Matthew Carl, and Jesse Smith for putting up with my daily antics. Last but not least, I bestow an enormous thank-you to my parents, Dr. Mikler and Dr. Mikler, for their love and support throughout my academic career thus far. 


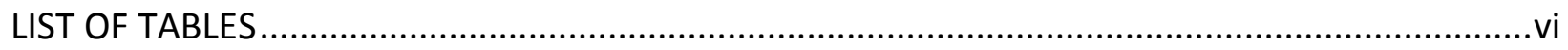

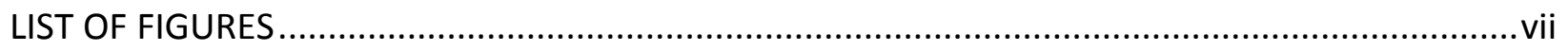

CHAPTER 1. INTRODUCTION TO MAGNETIC MATERIALS ................................................... 1

Introduction to Additive Manufacturing .................................................................... 3

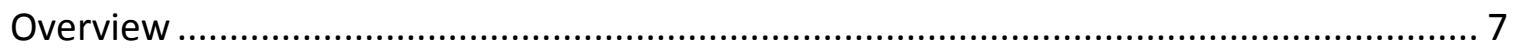

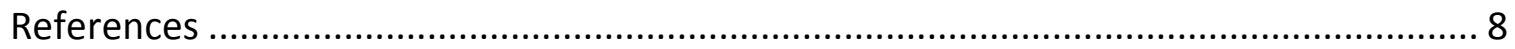

CHAPTER 2. MATERIALS AND METHODS: LASER ENGINEERED NET SHAPING ......................... 13

CHAPTER 3. MAGNETIC PROPERTIES AND PHASE STABILITY OF ADDITIVELY MANUFACTURED Fe-

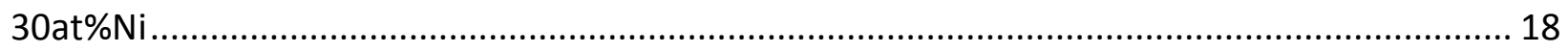

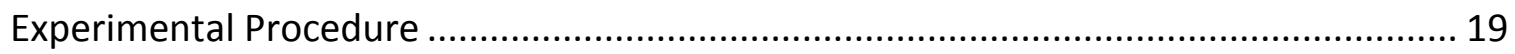

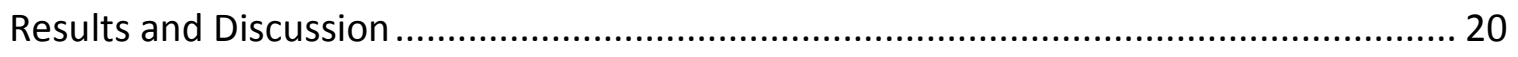

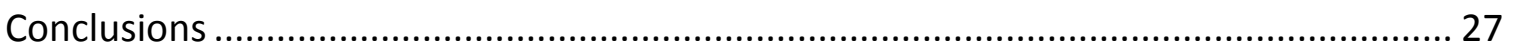

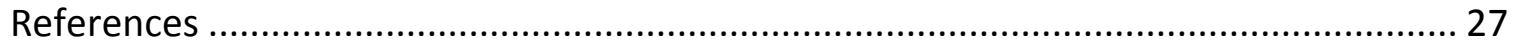

CHAPTER 4. Ni-Fe-Mo AND Ni-Fe-V PERMALLOYS VIA LASER ADDITIVE MANUFACTURING ....... 30

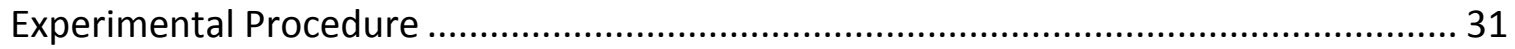

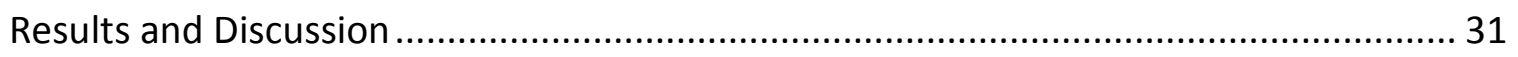

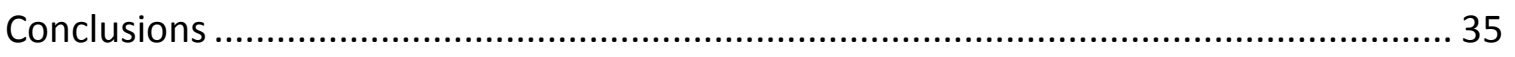

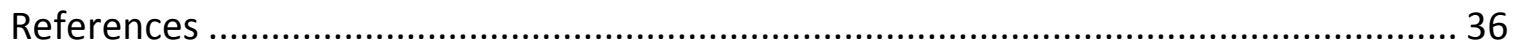

CHAPTER 5. A COMBINATORIAL APPROACH FOR ASSESSING THE MAGNETIC PROPERTIES OF

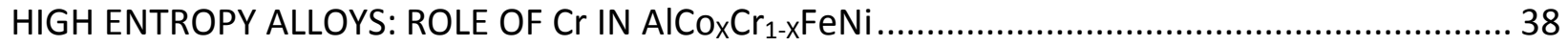

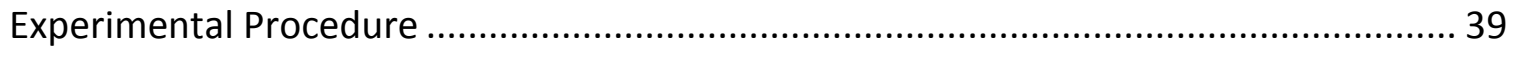

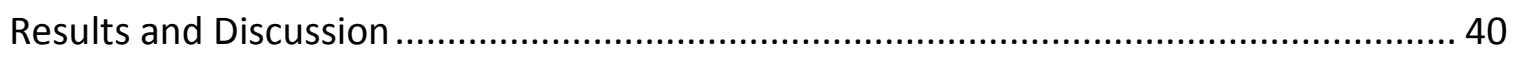

Microstructural Evolution and Its Impact on Magnetization in $\mathrm{AlCo}_{x} \mathrm{Cr}_{1-\mathrm{x}} \mathrm{FeNi}$................ 53

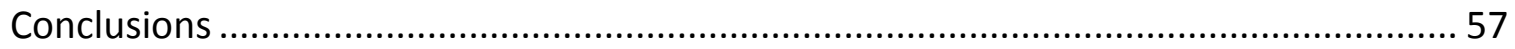

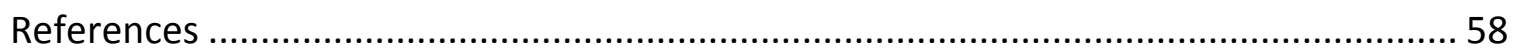


CHAPTER 6. CONCLUDING REMARKS .

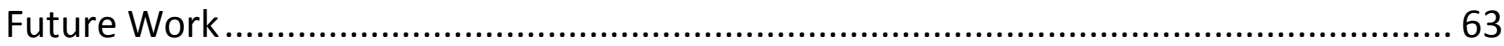




\section{LIST OF TABLES}

Page

Table 2.1: High purity metallic powders used for laser additive manufacturing ....................... 17

Table 3.1: Saturation magnetization $\left(M_{s}\right)$ and coercivity $\left(H_{c}\right)$ values as a function of processing

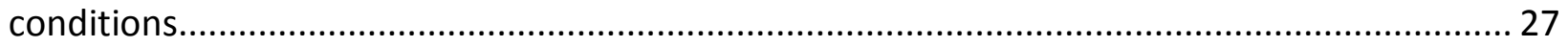




\section{LIST OF FIGURES}

Page

Figure 1.1: Schematic magnetization hysteresis curves for hard and soft magnetic materials..... 2

Figure 2.1: Schematic of LENS ${ }^{\text {TM }}$ system showing powder feeders, laser, glove box, and 3-axis stage 13

Figure 2.2: Close-up schematic of LENS ${ }^{\mathrm{TM}}$ welding head showing laser path, delivery nozzles, substrate, and a compositionally graded cylindrical sample. 14

Figure 3.1: Low temperature Fe-Ni phase diagram. 18

Figure 3.2: : X-ray diffraction spectra for LENS ${ }^{\mathrm{TM}}$ deposited Fe-30at\%Ni (a) 300W 5, 8 ,13, and 20IPM conditions and (b) 500W 5, 8, 13, 20IPM conditions

Figure 3.3: SEM micrograph of (a) 500W/8IPM sample, (b) TEM micrograph of precipitate with diffraction patters in (c) and (d), and SEM micrograph of (e) 300W/13IPM......

Figure 3.4: SEM-EBSD maps shown: 500W/8IPM phase map (a) and IPF map (b), 300W/13IPM phase map (c) and IPF map (d), and 500W/20IPM phase map (e) and IPF map (f).....

Figure 3.5: Magnetization versus magnetic field strength for (a) 300W conditions and (b) 500W conditions produced by vibrating scanning magnetometry. 25

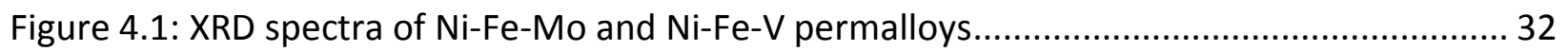

Figure 4.2: SEM micrographs of deposited (a)Ni-Fe-V and (b) Ni-Fe-Mo permalloy ................. 32

Figure 4.3: Selected area diffraction pattern and bright field TEM images of Ni-Fe-V $(a, b)$ and

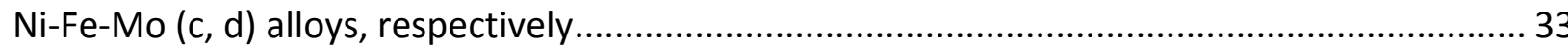

Figure 4.4: VSM magnetization curves for (a) deposited Ni-15Fe-V and (b) Ni-15Fe-Mo.......... 34

Figure 5.1: (a) Composition gradient in the as-deposited $\mathrm{AlCO}_{x} \mathrm{Cr}_{1-\mathrm{x}} \mathrm{FeNi}$ graded alloy, based on SEM-EDS measurements (b) XRD patterns from site specific locations (compositions) along the LENS $^{\mathrm{TM}}$ deposited $\mathrm{AlCo}_{\mathrm{x}} \mathrm{Cr}_{1-\mathrm{x}} \mathrm{FeNi}$ graded alloy

Figure 5.2: Backscattered SEM microstructure of the six different selected regions $(x=1,0.8,0.6$, $0.4,0.2$, and 0 ) of the graded $\mathrm{AlCo}_{\mathrm{x}} \mathrm{Cr}_{1-\mathrm{x}} \mathrm{FeNi}$ alloy 42

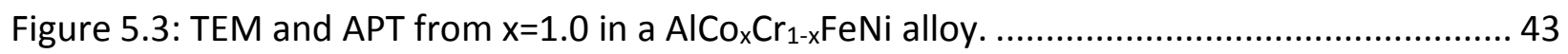

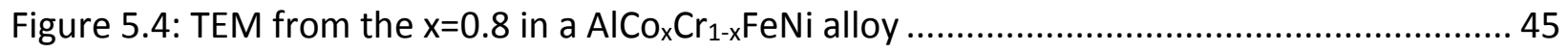

Figure 5.5: Grain boundary region TEM from the $\mathrm{x}=0.8$ in a $\mathrm{AlCo}_{\mathrm{x}} \mathrm{Cr}_{1-\mathrm{x}} \mathrm{FeNi}$ alloy..................... 46 
Figure 5.6: TEM and APT from the $x=0.4$ in a $\mathrm{AlCo}_{x} \mathrm{Cr}_{1-\mathrm{x}} \mathrm{FeNi}$ alloy.....

Figure 5.7: TEM and APT from the $\mathrm{x}=0$ in a $\mathrm{AlCo}_{\mathrm{x}} \mathrm{Cr}_{1-\mathrm{x}} \mathrm{FeNi}$ alloy......

50

Figure 5.8: (a) Magnetizations (M) as a function of applied magnetic field $(H)$ at temperatures of $300 \mathrm{~K}$ for NiAlFeCoxCr1-x ( $\mathrm{x}=0,0.2,0.4,0.6,0.8$ and 1); (b) show the saturation magnetizations (MS) and Coercivity ( $\mathrm{HC}$ ) as a function of Co concentration ( $\mathrm{X}=0$ to 1 ), respectively, at $300 \mathrm{~K}$. (c) Magnetization as a function of temperature at a magnetic field of $0.1 \mathrm{~T}$ in the temperature range from $\mathrm{RT}$ to $973 \mathrm{~K} \&$ (d) the variation of Curie temperature with the Co concentration in NiAlFeCo $\mathrm{Cr}_{1-\mathrm{x}}(\mathrm{x}=0,0.2,0.4,0.6,0.8$ and 1$)$.......... 


\section{CHAPTER 1}

\section{INTRODUCTION TO MAGNETIC MATERIALS}

Magnetic materials have been known about for several thousand years, beginning with lodestone, a naturally magnetized piece of magnetite $\left(\mathrm{Fe}_{2} \mathrm{O}_{3}\right)$ and maghemite $\left(\mathrm{Fe}_{2} \mathrm{O}_{3}\right)^{1-3}$. Not until 1819, however, was the relationship between magnetic and electric fields discovered by Professor Hans Christian Ørsted at the University of Copenhagen. The last almost two centuries (since $\varnothing$ rsted), have witnessed significant strides in magnetic materials development. Magnets now are enormously widespread in society, as critical components in computers, telephones, and switches; they are also parts crucial for energy generation and transmission, such as generators and transformer cores, respectively ${ }^{4,5}$. Their widespread necessity has led to different classes of magnet development and research. The two major classes of magnets are hard and soft; each has several key characteristics.

Hard magnets typically find use on refrigerators, in loudspeakers, as magnetic card strips in credit cards, and in hard drives. Soft magnetic materials are often used in read/write heads for hard drives; and probably most importantly, as transformers for power transmission. Characteristic magnetization or magnetic hysteresis curves for both soft and hard magnets are shown in figure 1.1 where $H$ is the applied magnetic field, typically with units of $A / m$ (amperes per meter); and $B$ is the magnetic flux density, typically in T (tesla) ${ }^{4}$. These curves, commonly generated by various types of magnetometers, gradually apply a magnetic field from $-|H|$ to $+|H|$ and measure the magnetic flux through the material. All hard and soft magnets feature a field strong enough that magnetic flux will not increase. This maximum magnetic flux is known as saturation magnetization $\left(M_{s}\right)$. When a field at which $M_{s}$ has been reached is achieved, the 
field reverses. When $H=0 \mathrm{~A} / \mathrm{m}$, there might still be magnetic flux through the material. This residual magnetic flux is known as remanence, or $B_{r}$. The amount of applied field to reduce (or increase) the magnetic flux $B$ back to zero is known as coercivity or coercive force, and is denoted as $H_{c}$.

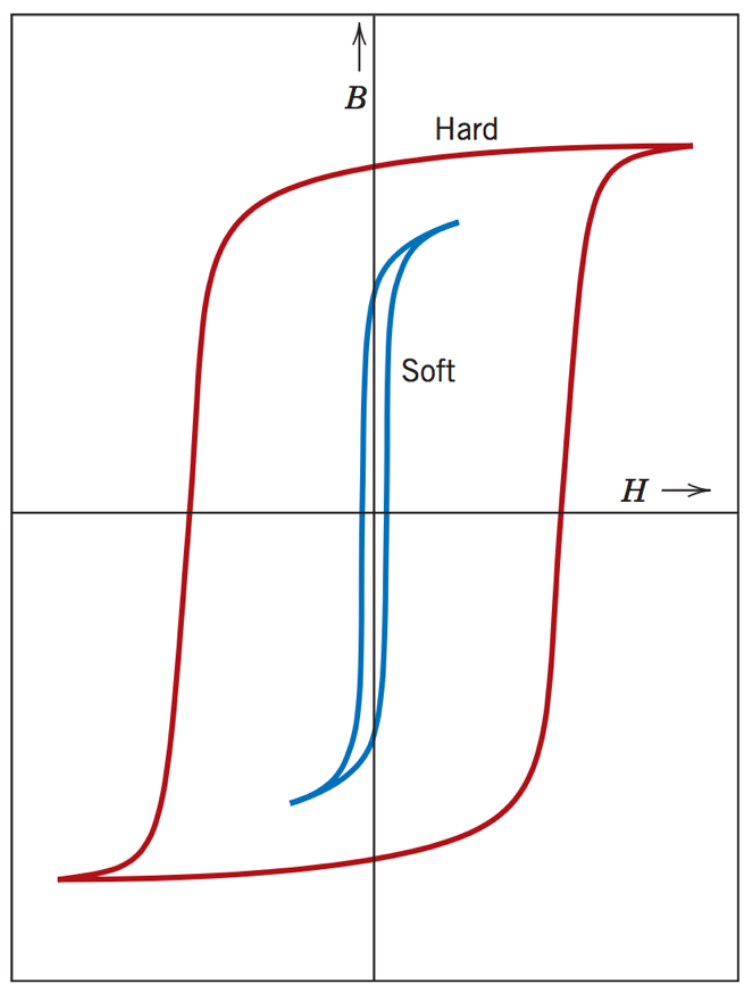

Figure 1.1: Schematic magnetization hysteresis curves for hard and soft magnetic materials. ${ }^{4}$

The most jarring differences between soft and hard magnets include the difference in coercivities as well as the overall area within the hysteresis curve. The area within the hysteresis curve is of particular importance due to it being the amount of magnetic energy loss per unit volume of material per magnetization-demagnetization cycle and its manifestation as heat generated in the magnet itself ${ }^{4,5}$. Hard magnetic materials such as the AINiCo series tend to stay magnetized for long periods of time due to the high energy requirement. For soft 
magnetic materials such as Fe-Si alloys, the area within the loop is very small, which is why they are commonly used in transformer cores.

These Fe-Si electric steels tend to have low electrical conductivities, which increase efficiency as a result of a reduction of eddy currents. An ideal transformer material would be an insulator to prevent eddy currents, have very low coercivity, and be easy to magnetize/demagnetize. Current transformer cores in the United States are typically rated as $120 / 240 \mathrm{~V}$ at $60 \mathrm{hz}{ }^{6,7}$.

The next generation of soft magnetic materials will require coercivities significantly less than what is now commercially available. Increasing the switching speed from $60 \mathrm{hz}$ to 10,000+hz will be required for higher efficiencies and transformer size reduction. For hard magnetic materials, the goal is to reduce or eliminate the use of rare-earth elements. These elements are expensive and often require destructive mining practices that destroy the environment ${ }^{8-10}$.

\section{Introduction to Additive Manufacturing}

Metal additive manufacturing (AM), also commonly known as 3D printing, is layer-bylayer manufacturing from a feedstock of powders, wires, or sheets. Many different techniques have been developed since the conception of 3D printing three decades ago. Two major types of powder metal additive manufacturing systems are commonly used today. Broadly, these two classifications include powder bed systems such as selective laser melting (SLM), and direct laser deposition (DLD) systems such as laser engineered net shaping (LENS ${ }^{\mathrm{TM}}$ ). The primary difference between the two systems is in how the powder is delivered: powder being a layer of 
powder where a laser selectively melts certain regions; and LENS being a blown powder technique where powders are injected into a melt pool produced by a laser. The three major problems that arise during the additive manufacturing process must be addressed: Residual porosity, columnar grains, and residual stresses.

The first problem is residual porosity during the melting process. Pockets of air can get trapped in the melt pool produced by the laser. While parts can still be manufactured reliably with $99 \%+$ densities, the lingering porosity can be detrimental to the structural integrity of critical components, especially in potential aerospace and biomedical applications ${ }^{11-14}$. Furthermore, delamination is also an issue between grains and layers of materials. Small cracklike pores can open on the grain boundaries. To combat and rid the microstructure of these microscopic pores, hot isostatic pressing (HIP) has been used to obtain a homogeneous and repeatable microstructure.

The second major issue is the manifestation of columnar grains that are a result of the additive manufacturing process. For many materials, the preferential growth direction in a melt generally follows the crystallographic direction with the highest thermal conductivity. For cubic $f c c$ and $b c c$, which are most commonly used in additive manufacturing, this direction is the $<001>^{15-18}$. Because of this preferred growth direction, significant texturing is evident in both electron backscatter diffraction (EBSD) and x-ray diffraction (XRD) analysis such that the (002) $f c c$ and $b c c$ planes dominate when analyzing a build parallel to the build direction. This texturing can present significant problems, especially when mechanical or functional isotropy is required. Complete control over grain structure has not yet been achieved. Attempts have been made to control the orientation of grains in specific alloys via variations in laser scan strategies 
and inoculants that act as heterogeneous nucleation sites for new grains ${ }^{19,20}$. For magnetic materials, this characteristic anisotropy from the printing process might be beneficial depending on the application, since devices such as transformers are purposefully made to be anisotropic ${ }^{4}$.

The third major challenge in additive manufacturing is residual stress. Additive manufacturing, depending on processing methodology, parameters, and build geometry, can yield far-from-equilibrium microstructures due to the rapid heating and cooling cycles of $10^{2}$ $10^{4} \mathrm{~K} / \mathrm{s}^{21-24}$. This rapid cooling may freeze the microstructure such that variations in lattice parameters are significant as compared to the ideal. This difference in lattice parameters manifests as residual stresses in the built components. In some cases, the magnitude of residual stress in a built part can exceed $50-80 \%$ of the yield stress of the material as measured by neutron diffraction ${ }^{25,26}$. This residual stress can easily be reduced via thermomechanical processing, such as annealing steps. The overall goal, however, is that additive manufacturing will create parts without the necessity of post processing. These three problems are currently being addressed worldwide via computational efforts to model the additive manufacturing process. Significant work has gone into modeling specific alloy powder sizes and characteristics as well as melt pool characteristics to model solidification processes.

On the physical research side, however, most worldwide R\&D activities related to additive manufacturing (AM) have focused on a rather limited set of alloys, such as stainless steels, certain nickel base superalloys, and conventional titanium alloys such as Ti-6Al-4V (wt\%) 27-31. Furthermore, these alloys have all been processed using pre-alloyed powder (or prealloyed wire) feedstock, and the efforts have been directed towards optimizing the powder 
characteristics (e.g., morphology, microstructure, composition, impurity content), deposition parameters, and laser scanning strategies, to achieve AM processed components with properties comparable to wrought or conventionally thermo-mechanically processed materials. While these efforts are extremely important for establishing AM as viable technologies for future manufacturing, the potential of these technologies remains underexploited in terms of their applicability to novel structural and functional material systems. Therefore, efforts need to focus on expanding the spectrum of metallic materials that can be processed using AM, with special consideration to processing novel magnetic materials.

Combinatorial techniques are also now widely used to characterize functional properties in thousands to millions of compositions in a single material library, but the strong dependence of structural properties on microstructures introduces length scale restrictions that vastly limit this approach for structural materials ${ }^{32-35}$. The most notable example has been in the area of functional materials where the semiconductor industry has exploited multi-target sputter deposition of thin films to rapidly assess the composition-structure-property relationships of multiple compositions for various device-related applications ${ }^{33,34}$. While such an approach is well suited for microelectronic devices, since the scale of the thin film being characterized and tested mimics that of eventual use, extension of the same approach to structural alloys for bulk applications is rather challenging. A major recent development in additive manufacturing is the advent of compositional gradation as a function of build for bulk metallic materials. For example, the use of blown powder techniques, such as LENS ${ }^{\mathrm{TM}}$, has confirmed that composition of the alloy can be gradually varied as a function of height. This combinatorial technique allows for entire alloy systems to be explored rapidly, without having to produce numerous samples 
individually ${ }^{36,37}$. While combinatorial techniques have mostly been used to develop complex concentrated (high entropy) alloys, they also allow for the exploration and accelerated maturation of any and all novel materials systems for both structural and functional purposes.

With regards to the development of rare-earth, free novel soft and hard magnetic materials, the field of high entropy implies potential solutions. Complex concentrated alloys (CCAs), or high entropy alloys (HEAs) came into the limelight in 2004 when the first two publications appeared, and these materials derived their names from the focus on configurational entropy ${ }^{38,39}$. The paradigm shift involved the approach of adding elements in equiatomic proportion to create solid-solution, face-centered-cubic (FCC) alloys. This method changed the old approach of adding elements to a 'parent' element to create alloys; for example, adding various amounts of chromium or carbon to iron to make steels. The complexity of the search space is captured with the increase in the number of elements. Thus for example, nine years elapsed since the report of the FCC HEA in 2004, before the first report of a hexagonal closed packed (HCP) HEA ${ }^{39,40}$. The majority of HEA research focuses on the mechanical properties; however, they can also be used for functional properties such as magnetism due to the amount of structures possible ${ }^{38-54}$.

\section{Overview}

This thesis focuses on three magnetic soft magnetic systems produced by laser engineered net shaping: Fe-30at\%Ni, Ni-Fe-V and Ni-Fe-Mo permalloys, and $\mathrm{AlCox}_{\mathrm{C}} \mathrm{r}_{1-\mathrm{x}} \mathrm{FeNi}$ high entropy alloy system. The second chapter is devoted to the laser engineered net shaping 
process and all the materials and methods involved with characterization of the deposited samples.

The third, fourth, and fifth chapters are devoted to the three magnetic alloy systems deposited: Fe-30at\%Ni, Ni-Fe-V and Ni-Fe-Mo, and AlCox $\mathrm{Cr}_{1-\mathrm{xFeNi}} \mathrm{Nespectively.} \mathrm{These} \mathrm{three}$ sections explore the microstructure/phase/magnetic properties relationships and demonstrate the viability of using additive manufacturing for not only the processing of commonly used magnetic materials, but also in the discovery of novel magnetic materials. The sixth chapter contains concluding remarks as well as a roadmap of prospective experiments that need to be completed.

\section{References}

1. Warner, T.E. Synthesis, properties, and mineralogy of important inorganic materials. (Wiley, 2011).

2. Wasilewski, P. \& Kletetschka, G. Lodestone: Nature's only permanent magnet-What it is and how it gets charged. Geophys. Res. Lett. 26, 2275-2278 (1999).

3. Livingston, J.D. Driving force : the natural magic of magnets. (Harvard University Press, 1996).

4. Callister, W.D. \& Rethwisch, D.G. Fundamentals of Materials Science and Engineering: An Integrated Approach. (John Wiley \& Sons, Inc., 2012).

5. Cullity, B.D. \& Graham, C.D. Introduction to Magnetic Materials. (John Wiley \& Sons, Inc., 2009).

6. Fink, D.G. \& Beaty, H.W. Standard handbook for electrical engineers. (McGraw-Hill, 1987).

7. McLyman, C.W.T. Transformer and inductor design handbook. (Marcel Dekker, 2004).

8. Gao, T.R. et al. Combinatorial exploration of rare-earth-free permanent magnets: Magnetic and microstructural properties of Fe-Co-W thin films. Appl. Phys. Lett. 102, 22419 (2013). 
9. Balamurugan, B., Das, B., Zhang, W.Y., Skomski, R. \& Sellmyer, D.J. Hf-Co and Zr-Co alloys for rare-earth-free permanent magnets. J. Phys. Condens. Matter 26, 64204 (2014).

10. Makino, A. et al. Artificially produced rare-earth free cosmic magnet. Sci. Rep. 5, 16627 (2015).

11. Louvis, E., Fox, P. \& Sutcliffe, C.J. Selective laser melting of aluminium components. J. Mater. Process. Technol. 211, 275-284 (2011).

12. Matthews, M.J. et al. Denudation of metal powder layers in laser powder bed fusion processes. Acta Mater. 114, 33-42 (2016).

13. Slotwinski, J.A., Garboczi, E.J. \& Hebenstreit, K.M. Porosity Measurements and Analysis for Metal Additive Manufacturing Process Control. 119, (2014).

14. Gu, D.D., Meiners, W., Wissenbach, K. \& Poprawe, R. Laser additive manufacturing of metallic components: materials, processes and mechanisms. Int. Mater. Rev. 57, 133164 (2012).

15. Vrancken, B., Thijs, L., Kruth, J.-P. \& Van Humbeeck, J. Microstructure and mechanical properties of a novel $\beta$ titanium metallic composite by selective laser melting. Acta Mater. 68, 150-158 (2014).

16. Zhang, Q. et al. Texture and microstructure characterization in laser additive manufactured Ti-6Al-2Zr-2Sn-3Mo-1.5Cr-2Nb titanium alloy. Mater. Des. 88, 550-557 (2015).

17. Niendorf, T. et al. Highly Anisotropic Steel Processed by Selective Laser Melting. Metall. Mater. Trans. B 44, 794-796 (2013).

18. Wei, H.L., Mazumder, J., DebRoy, T., Medraj, M. \& Raymont, D. Evolution of solidification texture during additive manufacturing. Sci. Rep. 5, 16446 (2015).

19. Porter, D.A. \& Easterling, K.E. Phase Transformations in Metals and Alloys. (CRC Press, 2009). doi:10.1007/978-1-4899-3051-4

20. Dehoff, R.R. et al. Site specific control of crystallographic grain orientation through electron beam additive manufacturing. Mater. Sci. Technol. 31, 931-938 (2015).

21. Zheng, B., Zhou, Y., Smugeresky, J.E., Schoenung, J.M. \& Lavernia, E.J. Thermal Behavior and Microstructure Evolution during Laser Deposition with Laser-Engineered Net Shaping: Part II. Experimental Investigation and Discussion. Metall. Mater. Trans. A 39, 2237-2245 (2008). 
22. Vilaro, T., Colin, C. \& Bartout, J.D. As-Fabricated and Heat-Treated Microstructures of the Ti-6Al-4V Alloy Processed by Selective Laser Melting. Metall. Mater. Trans. A 42, 31903199 (2011).

23. Zheng, B., Zhou, Y., Smugeresky, J.E., Schoenung, J.M. \& Lavernia, E.J. Thermal Behavior and Microstructural Evolution during Laser Deposition with Laser-Engineered Net Shaping: Part I. Numerical Calculations. Metall. Mater. Trans. A 39, 2228-2236 (2008).

24. Griffith, M. . et al. Understanding thermal behavior in the LENS process. Mater. Des. 20, 107-113 (1999).

25. Rangaswamy, P., Holden, T.M. \& Rogge, R.B. Residual stresses in components formed by the laser- engineered net shaping ( LENS 1 ) process. 38, 519-527 (2001).

26. Pratt, P., Felicelli, S.D., Wang, L. \& Hubbard, C.R. Residual Stress Measurement of LaserEngineered Net Shaping AISI 410 Thin Plates Using Neutron Diffraction. 39, 3155-3163 (2008).

27. Wong, K.V. \& Hernandez, A. A Review of Additive Manufacturing. ISRN Mech. Eng. 2012, 1-10 (2012).

28. Frazier, W.E. Metal Additive Manufacturing: A Review. J. Mater. Eng. Perform. 23, 19171928 (2014).

29. Sames, W.J., List, F.A., Pannala, S., Dehoff, R.R. \& Babu, S.S. The metallurgy and processing science of metal additive manufacturing. Int. Mater. Rev. 61, 315-360 (2016).

30. Banerjee, R., Collins, P., Bhattacharyya, D., Banerjee, S. \& Fraser, H. Microstructural evolution in laser deposited compositionally graded $\alpha / \beta$ titanium-vanadium alloys. Acta Mater. 51, 3277-3292 (2003).

31. Banerjee, R., Bhattacharyya, D., Collins, P., Viswanathan, G., \& Fraser, H. Precipitation of grain boundary $\alpha$ in a laser deposited compositionally graded Ti-8Al-xV alloy - an orientation microscopy study. Acta Mater. 52, 377-385 (2004).

32. ZHAO, J. Combinatorial approaches as effective tools in the study of phase diagrams and composition-structure-property relationships. Prog. Mater. Sci. 51, 557-631 (2006).

33. Deng, Y.P. et al. A combinatorial thin film sputtering approach for synthesizing and characterizing ternary ZrCuAl metallic glasses. Intermetallics 15, 1208-1216 (2007).

34. Ludwig, A., Zarnetta, R., Hamann, S., Savan, A. \& Thienhaus, S. Development of multifunctional thin films using high-throughput experimentation methods. Int. J. Mater. Res. 99, 1144-1149 (2008). 
35. Curtarolo, S. et al. The high-throughput highway to computational materials design. Nat. Mater. 12, 191-201 (2013).

36. Borkar, T. et al. A combinatorial assessment of AlxCrCuFeNi2 $(0<x<1.5)$ complex concentrated alloys: Microstructure, microhardness, and magnetic properties. Acta Mater. 116, 63-76 (2016).

37. Choudhuri, D. et al. Change in the primary solidification phase from fcc to bcc-based B2 in high entropy or complex concentrated alloys. Scr. Mater. 127, 186-190 (2017).

38. Yeh, J.-W. et al. Nanostructured High-Entropy Alloys with Multiple Principal Elements: Novel Alloy Design Concepts and Outcomes. Adv. Eng. Mater. 6, 299-303 (2004).

39. Cantor, B., Chang, I.T.H., Knight, P. \& Vincent, A.J.B. Microstructural development in equiatomic multicomponent alloys. Mater. Sci. Eng. A 375-377, 213-218 (2004).

40. Zhang, Y. et al. Microstructures and properties of high-entropy alloys. Prog. Mater. Sci. 61, 1-93 (2014).

41. Senkov, O.N., Miller, J.D., Miracle, D.B. \& Woodward, C. Accelerated exploration of multiprincipal element alloys for structural applications. Calphad Comput. Coupling Phase Diagrams Thermochem. 50, 32-48 (2015).

42. Embury, J.D., Deschamps, A. \& Brechet, Y. The interaction of plasticity and diffusion controlled precipitation reactions. Scr. Mater. 49, 927-932 (2003).

43. Miracle, D. et al. Exploration and Development of High Entropy Alloys for Structural Applications. Entropy 16, 494-525 (2014).

44. Guo, S., Ng, C. \& Liu, C.T. Sunflower-like Solidification Microstructure in a Near-eutectic High-entropy Alloy. Mater. Res. Lett. 1, 228-232 (2013).

45. Guo, S., Ng, C. \& Liu, C. T. Anomalous solidification microstructures in Co-free AlxCrCuFeNi2 high-entropy alloys. J. Alloys Compd. 557, 77-81 (2013).

46. Ng, C., Guo, S., Luan, J., Shi, S. \& Liu, C. T. Entropy-driven phase stability and slow diffusion kinetics in an Al0.5CoCrCuFeNi high entropy alloy. Intermetallics 31, 165-172 (2012).

47. Tong, C., Chen, Y., Yeh, J. \& Lin, S. Microstructure characterization of Al x CoCrCuFeNi high-entropy alloy system with multiprincipal elements. Mater. Trans. A 36, (2005).

48. Ranganathan, S. Alloyed pleasures: Multiatomic cocktails. Curr. Sci. 85, 1404-1406 (2003).

49. Tsai, M.-H. Physical Properties of High Entropy Alloys. Entropy 15, 5338-5345 (2013). 
50. Singh, S., Wanderka, N., Murty, B.S., Glatzel, U. \& Banhart, J. Decomposition in multicomponent AlCoCrCuFeNi high-entropy alloy. Acta Mater. 59, 182-190 (2011).

51. Tung, C.-C. et al. On the elemental effect of AlCoCrCuFeNi high-entropy alloy system. Mater. Lett. 61, 1-5 (2007).

52. Sriharitha, R., Murty, B.S. \& Kottada, R.S. Phase formation in mechanically alloyed AlxCoCrCuFeNi ( $x=0.45,1,2.5,5$ mol) high entropy alloys. Intermetallics 32, 119-126 (2013).

53. Cantor, B. Multicomponent and High Entropy Alloys. Entropy 16, 4749-4768 (2014).

54. Tsai, C.-W. et al. Deformation and annealing behaviors of high-entropy alloy Al0.5CoCrCuFeNi. J. Alloys Compd. 486, 427-435 (2009). 


\section{CHAPTER 2}

\section{MATERIALS AND METHODS: LASER ENGINEERED NET SHAPING}

Laser engineered net shaping (LENS ${ }^{\mathrm{TM}}$ ) is a direct laser deposition (DLD) additive manufacturing technology developed initially at Sandia National Laboratories in New Mexico, but is now trademarked and continuously developed by Optomec INC, in Albuquerque, NM. The LENS ${ }^{\mathrm{TM}}$ process has had great success and impact in rapid prototyping and small-batch production of relatively complex metallic parts in industry. Several key parts that are necessary for the operation of the LENS ${ }^{\text {TM }}$ system include the glove box, multi-axis stage, powder delivery system, and laser. A schematic of the LENS ${ }^{\mathrm{TM}}$ system can be found in figure 2.1 and a close-up of the weld head assembly in figure 2.2.

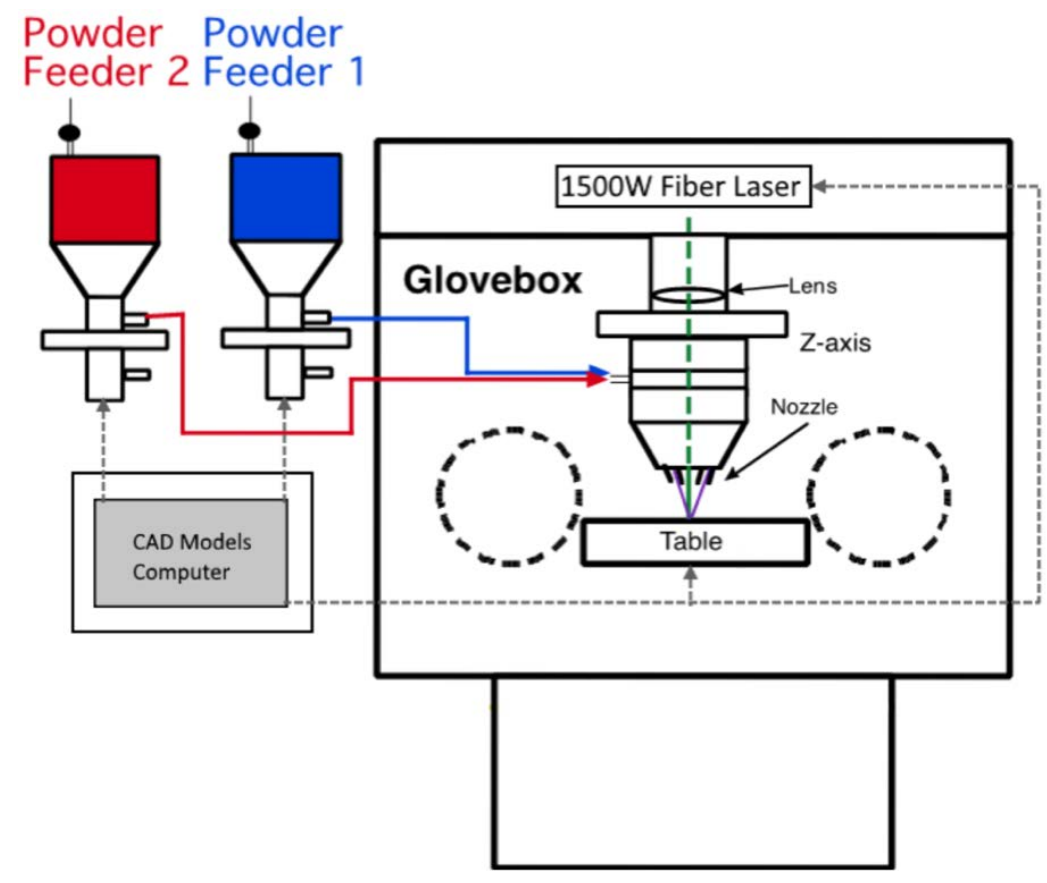

Figure 2.1: Schematic of LENS ${ }^{\mathrm{TM}}$ system showing powder feeders, laser, glove box, and 3-axis stage. 


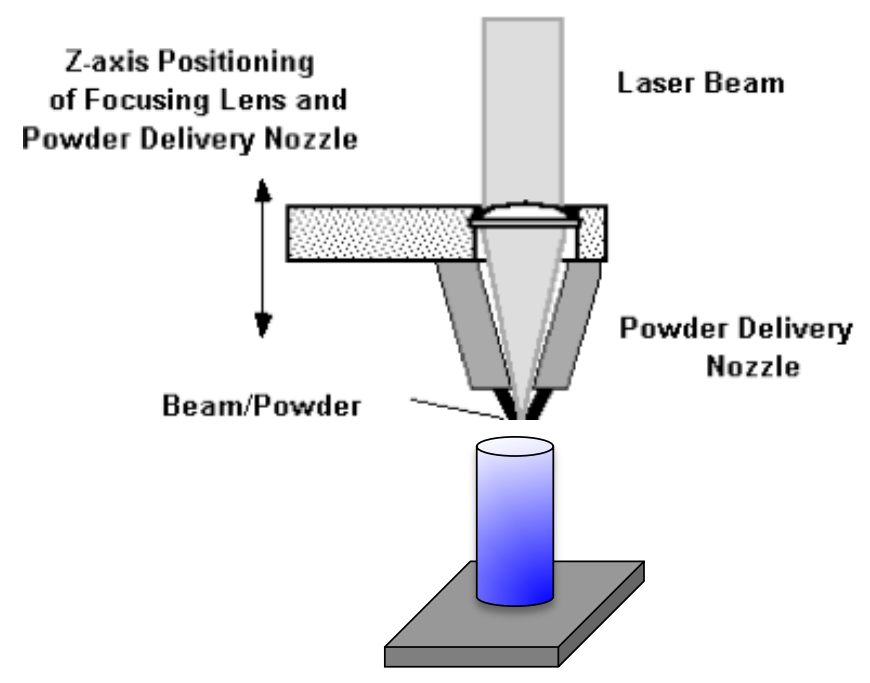

Figure 2.2: Close-up schematic of LENS ${ }^{\mathrm{TM}}$ welding head showing laser path, delivery nozzles, substrate, and a compositionally graded cylindrical sample

The process begins with a 3-dimensional computer aided design (CAD) file of the desired part to be built, much like in conventional polymer 3D printing. This part is sliced into layers using specialized software, where each layer is $0.254 \mathrm{~mm}(0.01$ inches) thick. Each layer is then assigned a specific tool path, reflecting the desired raster pattern. This code is then processed by the LENS ${ }^{\text {TM }}$ control software and is sent to a digital-analog converter (DAC), which controls the 3-axis screw-drive motors.

A retrofitted high powered 1500W fiber laser produced by IPG Photonics with a wavelength of $1064 \mathrm{~nm}$ is coupled to the LENS ${ }^{\mathrm{TM}}$ using a custom coupling, replacing the original 500W Nd:YAG laser. This laser is focused on the surface of a substrate, attached to the 3-axis stage. The spot size of the laser when focused is approximately $0.5 \mathrm{~mm}$ in diameter with a Gaussian power distribution over the circular region. This creates a melt pool on the surface into which metallic powders are directed. 
The powder delivery system is the most intricate of all conventional additive manufacturing systems. Key components of the powder feeders include a motor, powder reservoir, and delivery disk. The metallic powders are inserted into the reservoir. When the motor is on, the powders flow into holes located on a spinning delivery disk. As the disk spins, the powder-filled holes reach a point where they are in a flow of argon, and are subsequently emptied. The flow of argon fluidizes the metallic powders and directs them into a manifold where all the metallic powders from all the powder hoppers are mixed. This mixture of powder is then directed to the deposition head located in the glove box and subsequently ejected into the melt pool through copper nozzles. This method produces a continuous flow of powder without interruption, allowing for continuous building of material. The amount of powder sent to the deposition head can be adjusted by changing the powder feeder motor speed and the flow rate of the argon. The glove box is pressurized with argon such that the oxygen partial pressure is less than $10 \mathrm{ppm}$, which prevents oxidation from occurring. This combination of computer-controlled axes, variable powder flow, and laser power allows for immense flexibility when depositing new materials.

For Fe-30at\%Ni, $1 / 2$ inch diameter cylinders $1 / 2$ inch tall were deposited on a cast iron substrate. The hatch width and layer spacing were kept at 0.015 inches and 0.010 inches, respectively. Variations in travel speed and power were such that a matrix of variably processed samples was generated. Travel speeds were 5 inches per minute (IPM), 8IPM, 13IPM, and 20IPM. Laser powers were $300 \mathrm{~W}$ and 500W. A blend of high purity elemental iron and nickel powders were mixed for 12 hours with steel balls to ensure a homogeneous mixture. 
For Ni-Fe-V and Ni-Fe-Mo permalloys, 1/2 inch diameter cylinders 1 inch tall were deposited on a nickel substrate. The hatch width and layer spacing were kept at 0.015 inches and 0.010 inches, respectively. These samples were deposited with laser power of $400 \mathrm{~W}$ and travel speed of 20IPM. A blend of high purity elemental iron, nickel, molybdenum, and vanadium powders was mixed for 12 hours to ensure a homogeneous mixture.

For the AlCoxCr1-xFeNi system, a $1 / 2$ inch diameter, 1 inch tall cylinder was deposited with a variation in composition. Two separate powder mixes were used, one AlCoFeNi and the other AlCrFeNi, which are the extreme compositions at $x=1$ and $x=0$, respectively. Two different powder feeders were used simultaneously for this deposition. The AlCoFeNi powder was placed in the first feeder while the AlCrFeNi was placed in the second feeder. Both powder feeders were calibrated such that at a certain motor speed, a build rate of 0.01 inches/layer was achieved for that feeder. A 10-step compositional gradation was performed such that the first 0.1 inches was using $100 \%$ of the AlCoFeNi powder feeder and $0 \%$ of the AlCrFeNi powder feeder. For 0.1-0.2 inches, $90 \%$ of the AICoFeNi powder feeder and $10 \%$ of the AlCrFeNi powder feeder were used. This continued until the last step where $0 \%$ of the AICoFeNi powder feeder and $100 \%$ of the AlCrFeNi powder feeder were used.

\begin{tabular}{|c|c|}
\hline Element & Manufacturer \\
\hline Aluminum & Atlantic Equipment Engineers \\
\hline Chromium & Atlantic Equipment Engineers \\
\hline Cobalt & Atlantic Equipment Engineers \\
\hline Iron & Atlantic Equipment Engineers \\
\hline Molybdenum & Atlantic Equipment Engineers \\
\hline Nickel & Atlantic Equipment Engineers \\
\hline Vanadium & Atlantic Equipment Engineers \\
\hline
\end{tabular}

Table 2.1: High purity metallic powders used for laser additive manufacturing 
All powders are high purity elemental powders from various sources with a size of 100325 mesh (approximately $40-150 \mu \mathrm{m}$ ). Table 2.1 shows the powders used as well as the manufacturer. The high cost pre-alloyed powders, while superior for use in additive manufacturing systems, precluded their use for this work.

After depositions, all deposits were sliced off the substrate using a Mitsubishi FX-10 electronic discharge machine (EDM), and were sliced centrally along the build axis (z-axis), such that the entirety of the cylinders could be analyzed with scanning electron microscopy (SEM) coupled with electron backscatter diffraction for phase and texturing analysis, $\mathrm{x}$-ray diffraction (XRD) for phase and lattice parameter calculations, transmission electron microscopy highmagnification imaging, and vibrating scanning magnetometery to generate magnetic hysteresis and temperature-dependent magnetic saturation curves.

The SEM used for this work was an FEI Nova NanoSEM 230 with a field emission electron gun capable of both secondary and backscatter imaging modes. The energy dispersive spectroscopy (EDS) and electron backscatter diffraction (EBSD) systems installed on this microscope are the EDAX Octane Elite and EDAX Hikari series, respectively. An FEI Nova 200 NanoLab focused ion beam (FIB)/SEM with a Ga ion beam produced liftouts for TEM analysis. An FEI Tecnai G2 F20 ST scanning TEM performed high-resolution diffraction analysis as well as elemental EDS analysis. A Lakeshore 7404 vibrating scanning magnetometer generated magnetic hysteresis curves at room temperature, while a Quantum Design physical properties measurement system generated non-room temperature magnetic hysteresis curves as well as temperature-dependent saturation magnetization curves. 


\section{CHAPTER 3}

\section{MAGNETIC PROPERTIES AND PHASE STABILITY OF ADDITIVELY MANUFACTURED Fe-30at\%Ni*}

Fe-Ni based soft magnetic alloys have been used extensively in numerous applications such as sensors, transformers, and inductive devices. ${ }^{1-4}$. These materials are also candidates for low-grade waste heat recovery, heat pumps, and near room temperature magnetic cooling systems ${ }^{5-10}$. Fe-Ni, Fe-Ni-B, Fe-Ni-Mn, Fe-Ni-Mo, Fe-Ni-Zr-B, Fe-Ni-Cr have been reported to exhibit higher relative cooling power than rare earth based magnetocaloric-materials ${ }^{7-12}$. The Fe-Ni low temperature phase diagram developed by Yang, Williams shows that the magnetic properties and Curie temperature of the $\mathrm{\gamma}$-phase are strongly composition-dependent ${ }^{13}$.

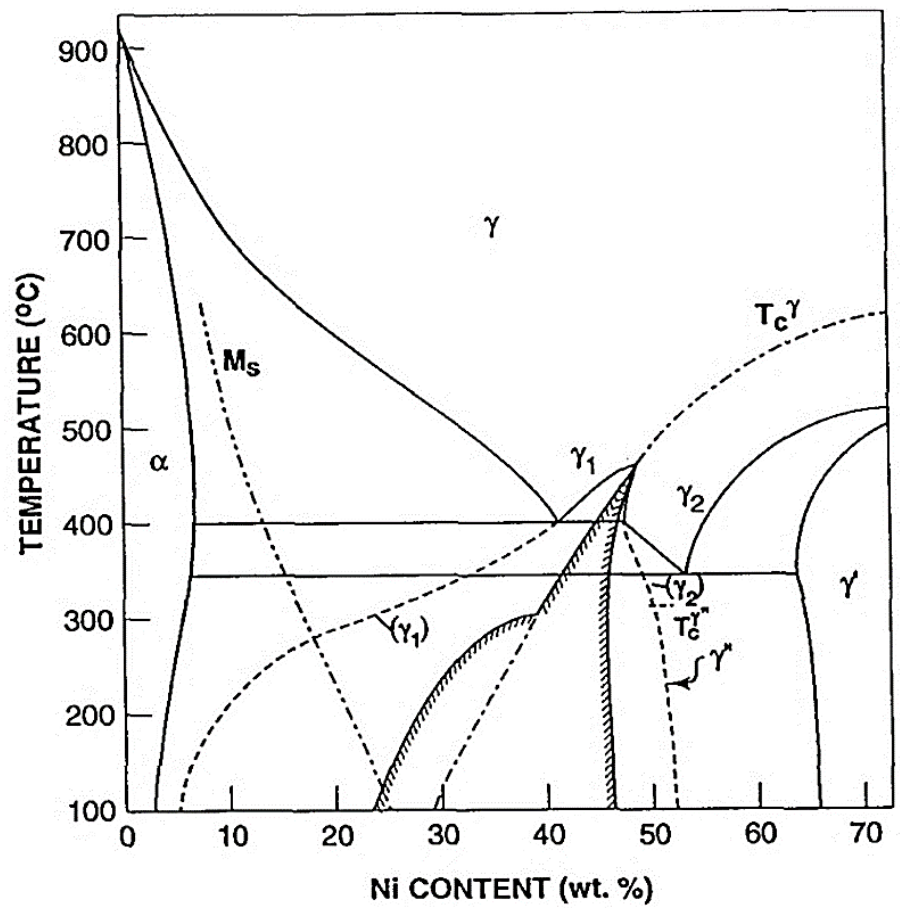

Figure 3.1: Low temperature Fe-Ni phase diagram ${ }^{13}$.

\footnotetext{
*Reproduced from Mikler et al., Tuning the phase stability and magnetic properties of laser additively processed
} Fe-30at\%Ni soft magnetic alloys. Materials Letters 199, (2017), with permission from Elsevier. 
$\mathrm{p}$-phase stabilization at room temperature on the Fe-rich side requires quenching from the $\gamma$-phase field $\left(>700^{\circ} \mathrm{C}\right)^{6-8} 14,15$. Zhang et al. investigated the microstructure and magnetic properties of the Fe-30at\%Ni alloy synthesized by selective-laser-melting ${ }^{2}$. Their x-ray diffraction (XRD) results confirmed that the bcc phase was dominant. Synthesizing bulk homogenous materials is another challenge that can result in a reduction of magnetic properties. Conventional techniques such as arc-melting, melt-spinning, and thermal-spraying can lead to excessive grain growth due to high-temperature processing ${ }^{16}$. It is therefore essential to investigate innovative processing/manufacturing technologies, such as LENS ${ }^{\mathrm{TM}}$ additive manufacturing (AM), capable of processing homogenous bulk material with good magnetic properties ${ }^{17,18}$. We study the effect of process parameters on the phase stability, microstructural evolution, and magnetic properties of LENS ${ }^{\mathrm{TM}}$ processed Fe-30at\%Ni alloy.

\section{Experimental Procedure}

Cylindrical deposits (10 $\mathrm{mm}$ diameter, $12-15 \mathrm{~mm}$ height) of elementally blended Fe30at\%Ni alloy were placed on a steel substrate using an Optomec LENS ${ }^{\mathrm{TM}}$ system coupled with an IPG YLS-1500 fiber laser. Oxygen levels were maintained below 10ppm during the deposition process to prevent oxidation. Two nominal laser powers (300W and 500W) and four travel speeds $(5,8,13$, and 20 inches per minute or IPM) were used to create eight variably processed samples. Hatch width and layer spacing were held constant for each deposit. Powder flow rates were manually calibrated to maintain a $0.01 \mathrm{in} /$ layer $(0.254 \mathrm{~mm} /$ layer $)$ build rate. All eight cylinders were sectioned longitudinally, parallel to the cylinder central axis. This center plane was analyzed in all cases. XRD studies were carried out in a Rigaku Ultima III x-ray 
diffractometer with $\mathrm{Cu}-\mathrm{Ka}$ source. Microstructure, composition, and phase analyses were carried out in an FEI Nova NanoSEM 230 FEG scanning electron microscope (SEM) equipped with an electron backscatter diffraction (EBSD) detector. A Lakeshore 7404 Vibrating scanning magnetometer (VSM) provided magnetometry at 300K under a 1.5T field.

\section{Results and Discussion}

XRD results from the deposited samples are shown in Fig. 3.2(a) for different travel speeds $(5,8,13,201 \mathrm{PM})$ at 300W power, and in Fig. 3.2(b) for 500W power.
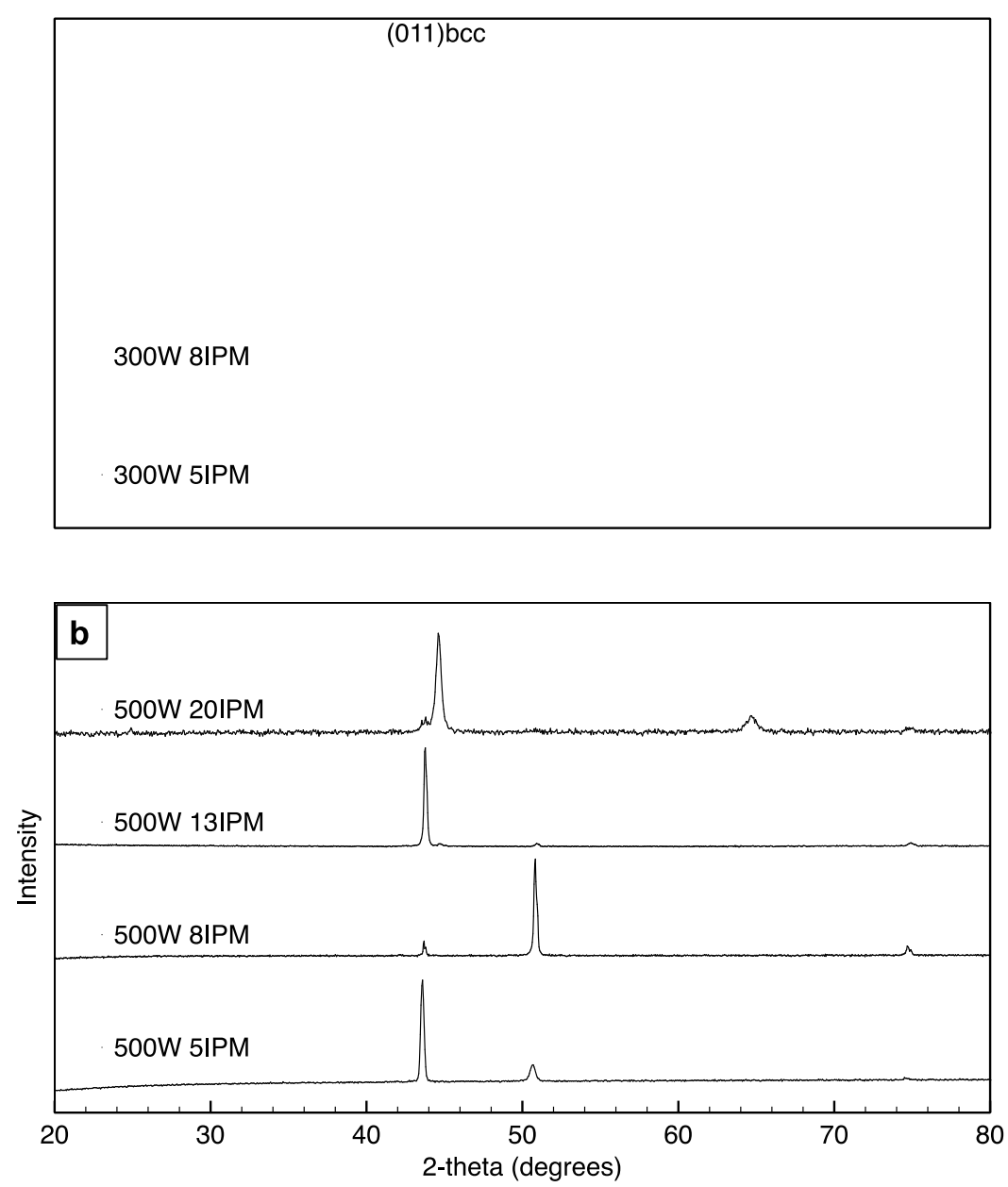

Figure 3.2: : X-ray diffraction spectra for LENS ${ }^{\mathrm{TM}}$ deposited Fe-30at\%Ni (a) 300W 5, 8 ,13, and 20IPM conditions and (b) 500W 5, 8, 13, 20IPM conditions 
In Fig. 3.2 (a), for lower travel speeds of 5IPM and 8IPM, the diffraction peaks can be indexed based on a single $f c c$ phase. For 13IPM, the pattern indicates a two-phase $f c c+b c c$ mixture. For 20IPM, a dominant $b c c$ phase is present. A similar trend can be observed in samples deposited using a power of 500W (Fig. 3.2 (b)), where increasing travel speed induces a progressive transition from a fcc-dominated structure to a bcc-dominated structure. The lattice parameters of the $f c c$ and $b c c$ phases were determined to be $a_{f c c}=0.3553 \mathrm{~nm}$ and $a_{b c c}=0.2866 \mathrm{~nm}$, respectively. Based on these XRD results, three candidate samples were identified for further microstructural analysis using SEM-EBSD. These were the 500W/8IPM sample, consisting primarily of the $f c c$ phase; the $300 \mathrm{~W} / 13$ IPM sample, containing a mixture of $f c c$ and $b c c$ phases; and the $500 \mathrm{~W} / 20$ IPM sample, which predominantly contained the bcc phase.

Fig. 3.3 shows SEM images, a bright field TEM (BFTEM) image, as well as representative selected area diffraction patterns (SADP) from the candidate samples. Fig. 3.3 (a) shows the microstructure of the 500W/8IPM sample, viewed along a direction normal to the axis of the cylindrical LENS ${ }^{\mathrm{TM}}$ deposit, clearly exhibiting columnar fcc grains.

Small precipitates, with size on the order of $200-500 \mathrm{~nm}$, are homogeneously distributed throughout the microstructure, as revealed by the higher magnification inset shown in Fig. 3.3 (a). The size and structure of these precipitates are more clearly visible in the BFTEM image (Fig. 3.3 (b)). Note the faceted nature of these precipitates within the $f c c$ matrix. Figs. 3.3 (c) and (d) show selected area electron diffraction patterns (SADPs) from the precipitate and the matrix, respectively. While Fig. 3.3 (d) can be indexed as the [011] zone axis of a disordered fcc solid solution phase, the fundamental reflections in Fig. 3.3 (c) can be indexed based on the [011] zone axis of a bcc phase. (Note the rectangular motif drawn on Fig. 3.3 (c).) However, note that, 
in addition to the fundamental bcc reflections, superlattice reflections at the $1 / 2(002)$, as well as at $1 / 4,1 / 2,3 / 4(112)$ positions, indicate that this bcc-based phase is chemically ordered (Fig. $3.3(\mathrm{c}))$. More detailed analysis is required to establish the true nature of ordering in these precipitates as well as their origin. SEM images of the 300W/13IPM sample are shown in Figs. 3.3 (e). The higher magnification image reveals the presence of two phases at a macroscopic scale, presumably the $f c c$ and $b c c$ phases, based on the x-ray diffraction analysis presented earlier. Furthermore, similar to the case of the 500W/8IPM sample, the small ordered bcc-based precipitates are also present in this case.
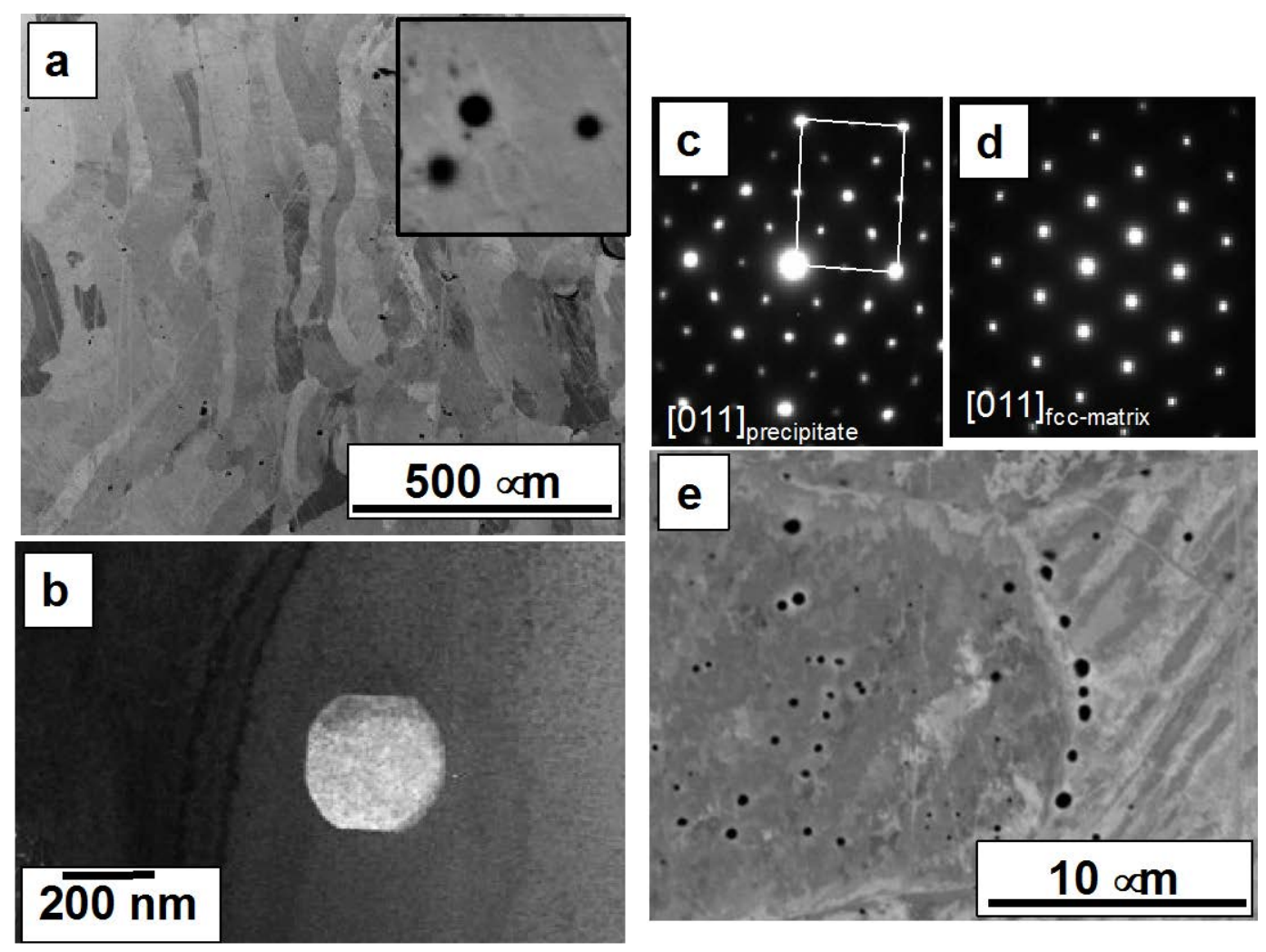

Figure 3.3: SEM micrograph of (a) 500W/8IPM sample, (b) TEM micrograph of precipitate with diffraction patters in (c) and (d), and SEM micrograph of (e) 300W/13IPM 
SEM-EBSD phase and inverse pole figure (IPF) maps for these samples are shown in Fig.

3.4. The phase map, with the $f c c$ and $b c c$ phases colored green and red, respectively, from the 500W/8IPM sample, is shown in Fig. 3.4 (a); while the orientation-dependent, pseudo-colored IPF map is shown in Fig. 3.4 (b).

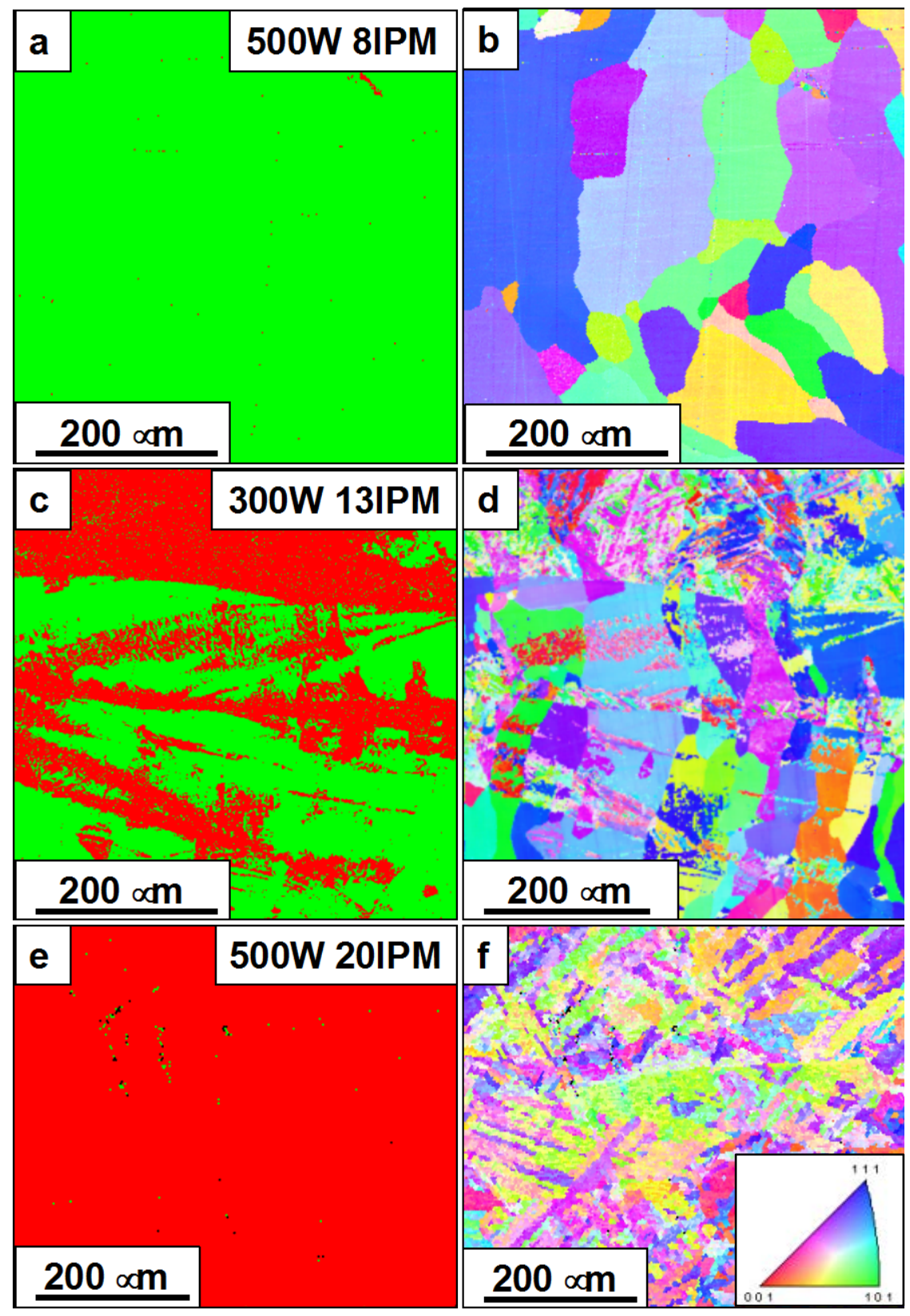

Figure 3.4: SEM-EBSD maps shown: 500W/8IPM phase map (a) and IPF map (b), 300W/13IPM phase map (c) and IPF map (d), and 500W/20IPM phase map (e) and IPF map (f) 
This confirms that columnar fcc grains are present for these deposition conditions. SEM-EBSD images of the 13IPM 300W sample are shown in Figs. 3.4 (c) and (d). The phase map (Fig. 3.4 (c)) presents both $f c c$ and $b c c$ phases. The IPF map (Fig. 3.4 (d)) establishes that lath-like regions of $b c c$ are within columnar $f c c$ grains. Analysis of the pole figures for a lath-like $b c c$ region and the surrounding columnar $f c c$ grain revealed an orientation relationship (OR) $\{111\} f c c / /\{011\} b c c$ and $<011>f c c / /<001>b c c$; i.e., the Nishiyama-Wasserman (N-W) OR, which is commonly observed between bcc martensitic plates and the parent $f c c$ austenite grain in many steels. The SEM-EBSD phase and IPF maps for the 500W/20IPM sample are shown in Figs. 3.4 (e) and (f), respectively. Under these deposition conditions, the microstructure consists predominantly of a single $b c c$ phase exhibiting a martensitic lath-like morphology.

At room temperature, the $f c c$ phase of $\mathrm{Fe}-30$ at $\% \mathrm{Ni}$ is a metastable ${ }^{18,19}$. The martensiticstart temperatures of this alloy are below room temperature, in the range of $-62^{\circ} \mathrm{C}$ to $-57^{\circ} \mathrm{C}^{19}$. Previous investigations on conventionally processed Fe-30at\%Ni alloy have established that martensitic transformations can occur during quenching or plastic deformation, starting from solution-treated $f c c$ austenite ${ }^{19}$. The LENS $^{\mathrm{TM}}$ as-deposited alloy in the 300W/13IPM and $500 \mathrm{~W} / 20$ IPM samples exhibited regions of martensite bcc plates within the $f c c$ grains at room temperature, above the martensitic-start temperature for this composition. Therefore, the martensite plates in this case are possibly attributable to stress or deformation-induced martensite. Since no macroscopic deformation is involved in this process, likely residual stresses generated during laser-deposition are responsible for the martensitic transformation.

Figs. 3.5 (a) and (b) show the magnetization versus applied magnetic field hysteresis loops for four selected deposition conditions. All samples exhibit a well-defined soft magnetic 
hysteresis loop with coercivities $\left(H_{c}\right)$ in the range of 21-30 Oe and saturation magnetizations

$\left(M_{s}\right)$ between 120-165 emu/g. The values of $M_{s}$ and $H_{c}$ for the four different deposition conditions are listed in Table 3.1.

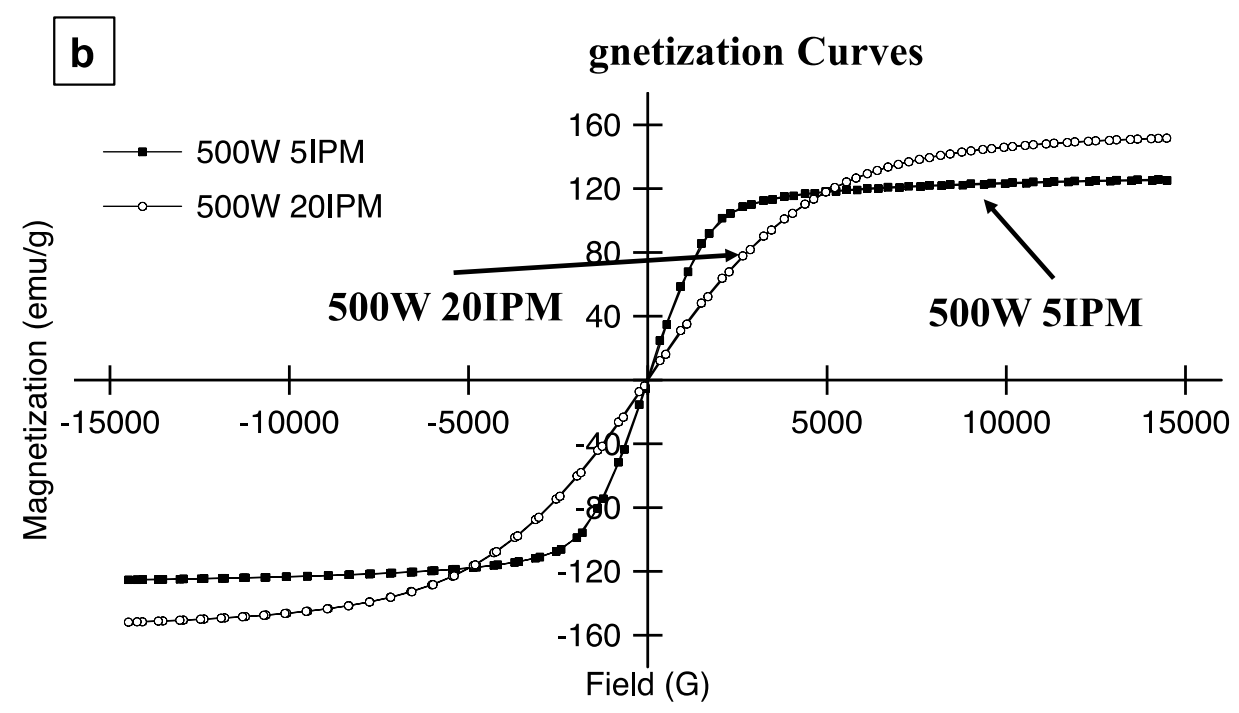

Figure 3.5: Magnetization versus magnetic field strength for (a) 300W conditions and (b) 500W conditions produced by vibrating scanning magnetometry 


\begin{tabular}{ccc}
\hline Processing condition & $\boldsymbol{M}_{\boldsymbol{s}}(\mathrm{emu} / \mathrm{g})$ & $\boldsymbol{H}_{\boldsymbol{c}}(\mathrm{Oe})$ \\
\hline 300W 5IPM & 120 & 30 \\
300W 20IPM & 165 & 26 \\
500W 5IPM & 125 & 19 \\
500W 20IPM & 152 & 21 \\
\hline
\end{tabular}

Table 3.1: Saturation magnetization $\left(\mathrm{M}_{s}\right)$ and coercivity $\left(H_{c}\right)$ values as a function of processing conditions

The $\mathrm{M}_{\mathrm{s}}$, for samples deposited using a 20IPM travel speed exhibiting primarily a bcc

microstructure are higher than those deposited at 5IPM, which predominantly exhibit an $f c c$ microstructure. The change in the $\mathrm{M}_{\mathrm{s}}$ can be attributed to a change in total magnetic moment from $1.15 \mu \mathrm{B} /$ atom for the pure $f c c$ phase to $1.87 \mu \mathrm{B} /$ atom for the pure $b c c$ phase ${ }^{19}$. The $\mathrm{H}_{c}$ values are marginally lower for the samples deposited using a power of 500W compared to those deposited using 300W. Magnetic anisotropy is influenced by processing parameters (laser power and travel speed) in terms of microstructural effects, such as texture and crystallographic-anisotropy arising from the two-phase structure, which can result in a variation in $\mathrm{H}_{\mathrm{c}}$ values.

Another cylinder of Fe-30at\%Ni was deposited with parameters 500W 20IPM. XRD analysis on a plane parallel to the build direction indicates majority bcc phase is present, with minor amounts of $f c c$. Six slices were taken from this second deposit, each approximately $2 \mathrm{~mm}$ in thickness. XRD spectra were taken from every slice, such that the spectra generated is from a plane perpendicular to the build axis instead of being averaged over the entirety of the build. At the base, XRD analysis indicates that the dominant phase is $b c c$ with no significant $f c c$ peaks. Spectra nearer to the center of the build indicate that the dominant phase is still $b c c$, however, 
there is increased fcc presence. Near the top of the sample, the dominant phase again transitions back to $b c c$ with almost no $f c c$ peaks. This phenomenon can be attributed to the non-uniform undercooling and temperature gradients that occur in LENS ${ }^{\mathrm{TM}}$ processing.

\section{Conclusions}

Using laser engineered net shaping (LENS $\left.{ }^{\mathrm{TM}}\right)$, Fe-30at\%Ni was deposited from a feedstock of blended elemental powders. Depending on process parameters, the microstructure can be tuned to be either fcc- or bcc-dominated with consequent impact on their $\mathrm{M}_{\mathrm{s}}$ and $\mathrm{H}_{\mathrm{c}}$ values. Lower travel speeds (e.g., 5IPM) result in an fcc-dominated microstructure exhibiting a lower $\mathrm{M}_{\mathrm{s}}$ value, while higher travel speeds (e.g., 20IPM) result in a bcc-dominated microstructure with a substantially higher $M_{s}$ value. The $H_{c}$ values exhibit a small tendency to be lower for higher deposition powers. These results demonstrate not only the ability to process these soft magnetic alloys via laser-based additive manufacturing, but also the ability to tune their microstructure and magnetic properties as a function of the processing parameters.

\section{References}

1. Arnold, H.D. \& Elmen, G.W. Permalloy, A New Magnetic Material of Very High Permeability. Bell Syst. Tech. J. 2, 101-111 (1923).

2. Zhang, B., Fenineche, N.-E., Zhu, L., Liao, H. \& Coddet, C. Studies of magnetic properties of permalloy (Fe-30\%Ni) prepared by SLM technology. J. Magn. Magn. Mater. 324, 495500 (2012).

3. Ripka, P. Sensors based on bulk soft magnetic materials: Advances and challenges. J. Magn. Magn. Mater. 320, 2466-2473 (2008).

4. McHenry, M.E., Willard, M.A. \& Laughlin, D.E. Amorphous and nanocrystalline materials for applications as soft magnets. Prog. Mater. Sci. 44, 291-433 (1999). 
5. Jones, N.J., Ucar, H., Ipus, J.J., McHenry, M.E. \& Laughlin, D.E. The effect of distributed exchange parameters on magnetocaloric refrigeration capacity in amorphous and nanocomposite materials. J. Appl. Phys. 111, 07A334 (2012).

6. Ucar, H. Metastable gamma-Iron Nickel Nanostructures for Magnetic Refrigeration Near Room Temperature. (Carnegie Mellon University, 2013).

7. Chaudhary, V., Chaturvedi, A., Sridhar, I. \& Ramanujan, R.V. Fe\&amp;\#x2013;Ni\&amp;\#x2013;Mn Nanoparticles for Magnetic Cooling Near Room Temperature. IEEE Magn. Lett. 5, 1-4 (2014).

8. Chaudhary, V., Maheswar Repaka, D.V., Chaturvedi, A., Sridhar, I. \& Ramanujan, R.V. Magnetocaloric properties and critical behavior of high relative cooling power FeNiB nanoparticles. J. Appl. Phys. 116, 163918 (2014).

9. Chaudhary, V. \& Ramanujan, R.V. Magnetic and structural properties of high relative cooling power (Fe $70 \mathrm{Ni} 30$ ) 92 Mn 8 magnetocaloric nanoparticles. J. Phys. D. Appl. Phys. 48, 305003 (2015).

10. Chaudhary, V. \& Ramanujan, R.V. High Relative Cooling Power in a Multiphase Magnetocaloric FeNiB Alloy. IEEE Magn. Lett. 6, 1-4 (2015).

11. Ipus, J.J., Ucar, H. \& McHenry, M.E. Near Room Temperature Magnetocaloric Response of an (FeNi)ZrB Alloy. IEEE Trans. Magn. 47, 2494-2497 (2011).

12. Ucar, H., Craven, M., Laughlin, D.E. \& McHenry, M.E. Effect of Mo Addition on Structure and Magnetocaloric Effect in $\gamma$-FeNi Nanocrystals. J. Electron. Mater. 43, 137-141 (2014).

13. Yang, C.W., Williams, D.B. \& Goldstein, J.I. A revision of the Fe-Ni phase diagram at low temperatures $\left(<400^{\circ} \mathrm{C}\right)$. J. Phase Equilibria 17, 522-531 (1996).

14. Kadau, K., Gruner, M., Entel, P. \& Kreth, M. Modeling Structural and Magnetic Phase Transitions in Iron-Nickel Nanoparticles. Phase Transitions 76, 355-365 (2003).

15. Miller, K.J., Sofman, M., McNerny, K. \& McHenry, M.E. Metastable $\gamma$-FeNi nanostructures with tunable Curie temperature. J. Appl. Phys. 107, 09A305 (2010).

16. Lee, G.-H. \& Kang, S. Sintering of nano-sized WC-Co powders produced by a gas reduction-carburization process. J. Alloys Compd. 419, 281-289 (2006).

17. Keicher, D.M. \& Miller, W.D. LENS ${ }^{\mathrm{TM}}$ moves beyond RP to direct fabrication. Met. Powder Rep. 53, 26-28 (1998).

18. Zhang, X.M. et al. Morphology transition of deformation-induced lenticular martensite in Fe-Ni-C alloys. Acta Metall. Mater. 41, 1693-1699 (1993). 
19. Wittridge, N.J. \& Jonas, J. J. The austenite-to-martensite transformation in $\mathrm{Fe}-30 \% \mathrm{Ni}$ after deformation by simple shear. Acta Mater. 48, 2737-2749 (2000). 


\section{CHAPTER 4}

\section{Ni-Fe-Mo AND Ni-Fe-V PERMALLOYS VIA LASER ADDITIVE MANUFACTURING*}

$\mathrm{Ni}-\mathrm{Fe}-\mathrm{Mo}$ and $\mathrm{Ni}-\mathrm{Fe}-\mathrm{V}$ permalloys and other soft magnetic materials are of considerable interest due to the large variety of applications in electromagnetic devices, including but not limited to sensors, transformers, and electric motors ${ }^{1-8}$. Conventional permalloys exhibit low coercivity, high permeability, and moderate saturation magnetizations ${ }^{9,10}$. X-ray diffraction, neutron diffraction, transmission electron microscopy, scanning electron microscopy, and Mössbauer spectroscopy ${ }^{11}$ show that short-range or long-range ordering in the alloy affects these properties. Magnetic properties also depend on synthesis techniques and parameters used. Zhang et al. found a change in the magnetic properties of Fe-Ni-Mo sputtered films by changing sputtering parameters such as gas pressure, bias, and temperature ${ }^{12}$. Transport measurements and magnetization dynamics suggest an enhancement of spin-orbit interactions in Pt doped $\mathrm{Ni}_{81} \mathrm{Fe}_{19}$ thin films ${ }^{9}$. Numerous approaches such as arc melting, ball milling, magnetron sputtering, and pulsed laser ablation improve the performance of these soft magnetic materials $13-18$

This section explores the feasibility of processing Ni-Fe- $\mathrm{V}$ and $\mathrm{Ni}-\mathrm{Fe}-\mathrm{Mo}$-based permalloys using the Laser Engineered Net Shaping (LENS ${ }^{\mathrm{TM}}$ ) process. The microstructure and magnetic properties of the LENS ${ }^{\text {TM }}$ deposited permalloys have been investigated and compared to those of conventionally processed permalloys.

\footnotetext{
${ }^{*}$ Reproduced from Mikler et al., Laser additive processing of Ni-Fe-V and Ni-Fe-Mo Permalloys: Microstructure and magnetic properties. Mater. Lett. 192, 9-11 (2017), with permission from Elsevier.
} 


\section{Experimental Procedure}

Cylindrical deposits $10 \mathrm{~mm}$ in diameter and $25 \mathrm{~mm}$ in height of nominal composition $\mathrm{Ni}$ 15Fe-5V and Ni-15Fe-5Mo were deposited using an Optomec LENS ${ }^{\mathrm{TM}} 750$ system coupled with a 500W Nd:YAG laser $(\lambda=1.064 \mu \mathrm{m})$. Operating parameters were $400 \mathrm{~W}$ of power and vector speed of 20 inches per minute (IPM), or approximately $0.5 \mathrm{~m} / \mathrm{s}$. Powder flow rates were calibrated to maintain a $0.025 \mathrm{~mm} /$ layer build rate. Elemental blends of iron, nickel, and vanadium/molybdenum in the size range of $40-150 \mu \mathrm{m}$ were deposited on a nickel plate substrate. An inert argon environment with less than 10ppm oxygen was maintained in the glovebox during the depositions.

An FEI Nova NanoSEM 230 SEM and an FEI Tecnai G2 F20 TEM enabled analysis of the microstructure. A Rigaku Ultima III X-Ray diffractometer (XRD) was used to obtain crystallographic and phase information. A Lakeshore 7404 vibrating scanning magnetometer (VSM) generated magnetic hysteresis curves at 300K under a 1T field.

Results and Discussion

XRD results from both deposited Ni-Fe-V and Ni-Fe-Mo samples are shown in Fig. 4.1. Diffraction peaks in both samples can be indexed based on an fcc phase with the (111), (002), and (022) fcc peaks visible within the scan range. The calculated lattice parameters of Ni-Fe-V are $a=3.5532 \AA$ and of Ni-Fe-Mo $a=3.5697 \AA$. 


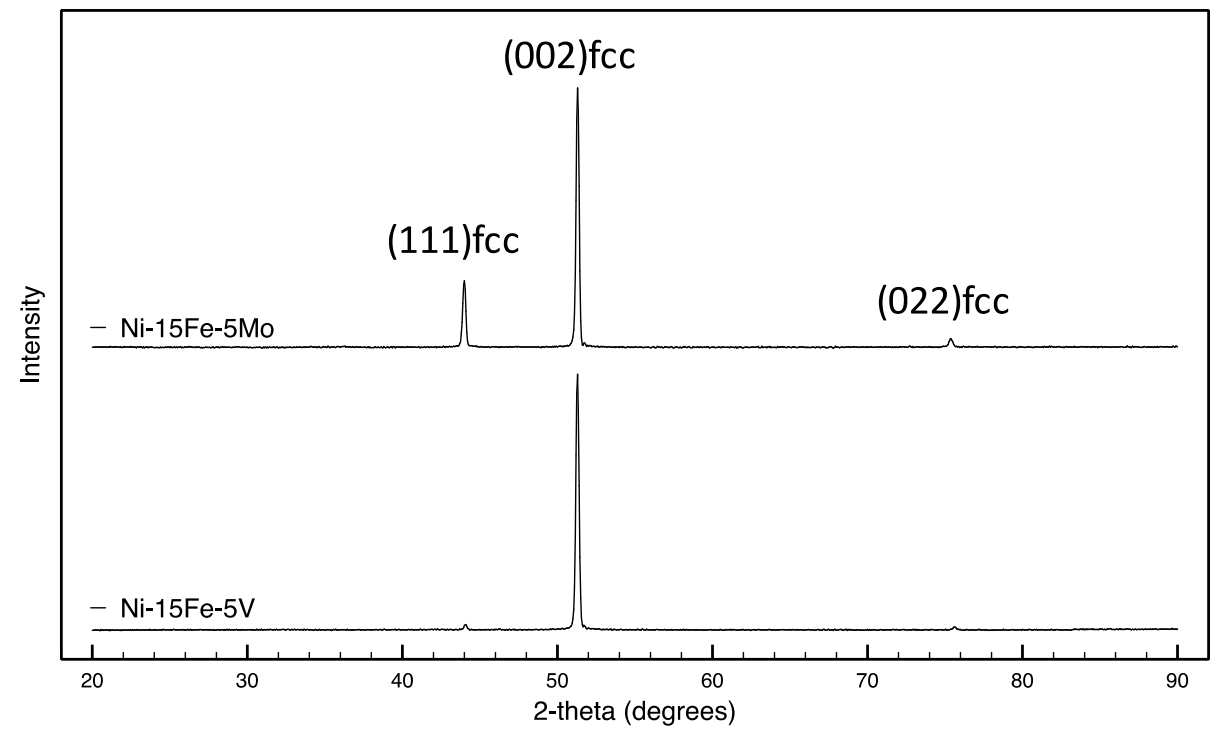

Figure 4.1: XRD spectra of Ni-Fe-Mo and Ni-Fe-V permalloys

SEM micrographs from these samples are shown in Fig. 4.2 (a) and (b).
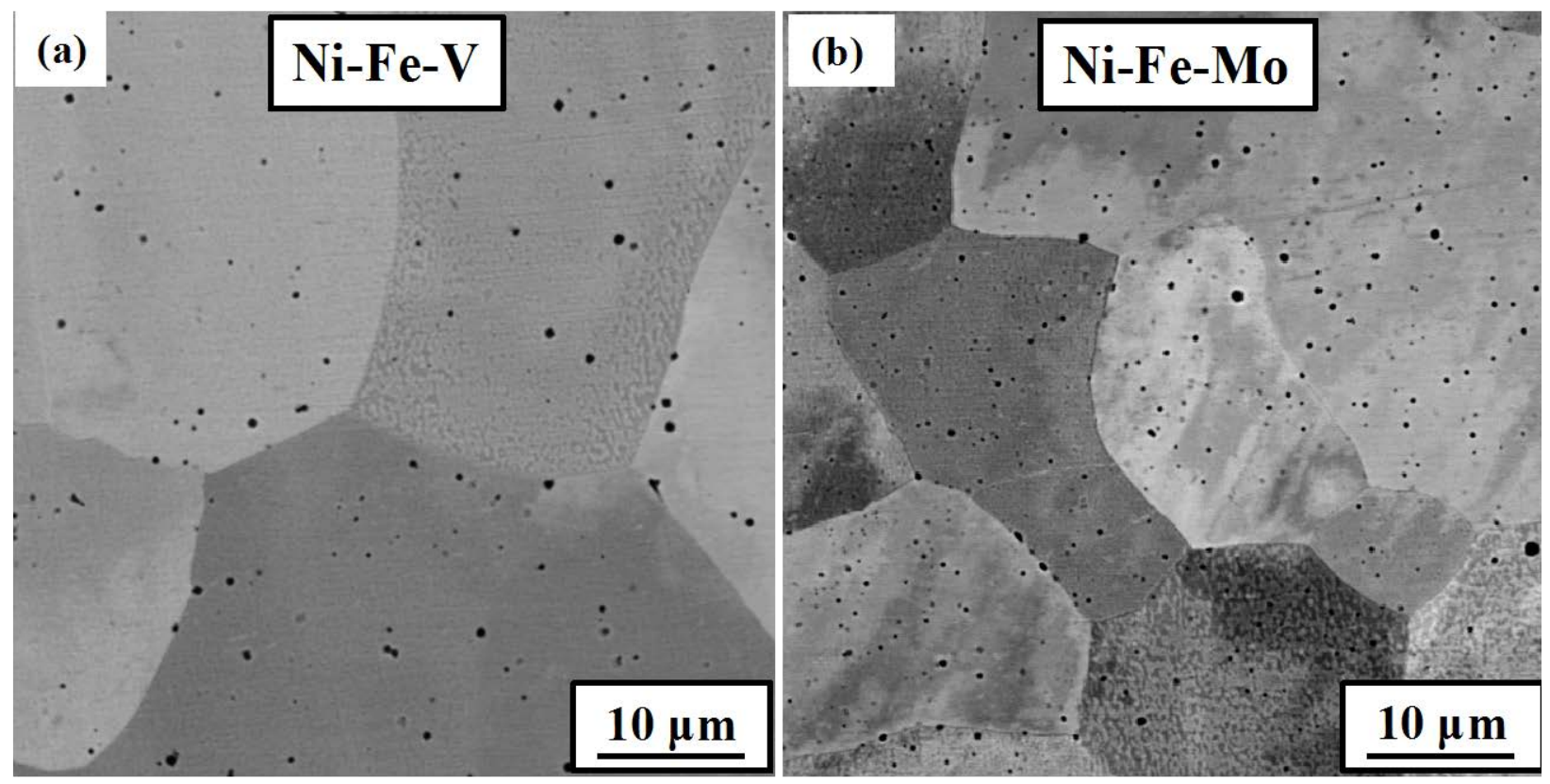

Figure 4.2: SEM micrographs of deposited (a)Ni-Fe-V and (b) Ni-Fe-Mo permalloy 
These microstructures are generally featureless and exhibit columnar fcc grains. A small volume fraction of second phase appears in the form of small scale precipitates that exhibit substantially darker contrast in these images. Energy dispersive spectroscopy (EDS) analysis of these samples, carried out in the SEM, revealed that the average compositions were $\mathrm{Ni}-18 \mathrm{Fe}-4 \mathrm{~V}$ (wt\%) and Ni-19Fe-5Mo (wt\%). Fig. 4.3 (a) shows a [011] zone axis electron diffraction pattern from the $f c c$ phase exhibiting a fundamental $f c c$ diffraction pattern; while Fig. 3(b) shows a bright-field image from the $\mathrm{Ni}-\mathrm{Fe}-\mathrm{V}$ sample.

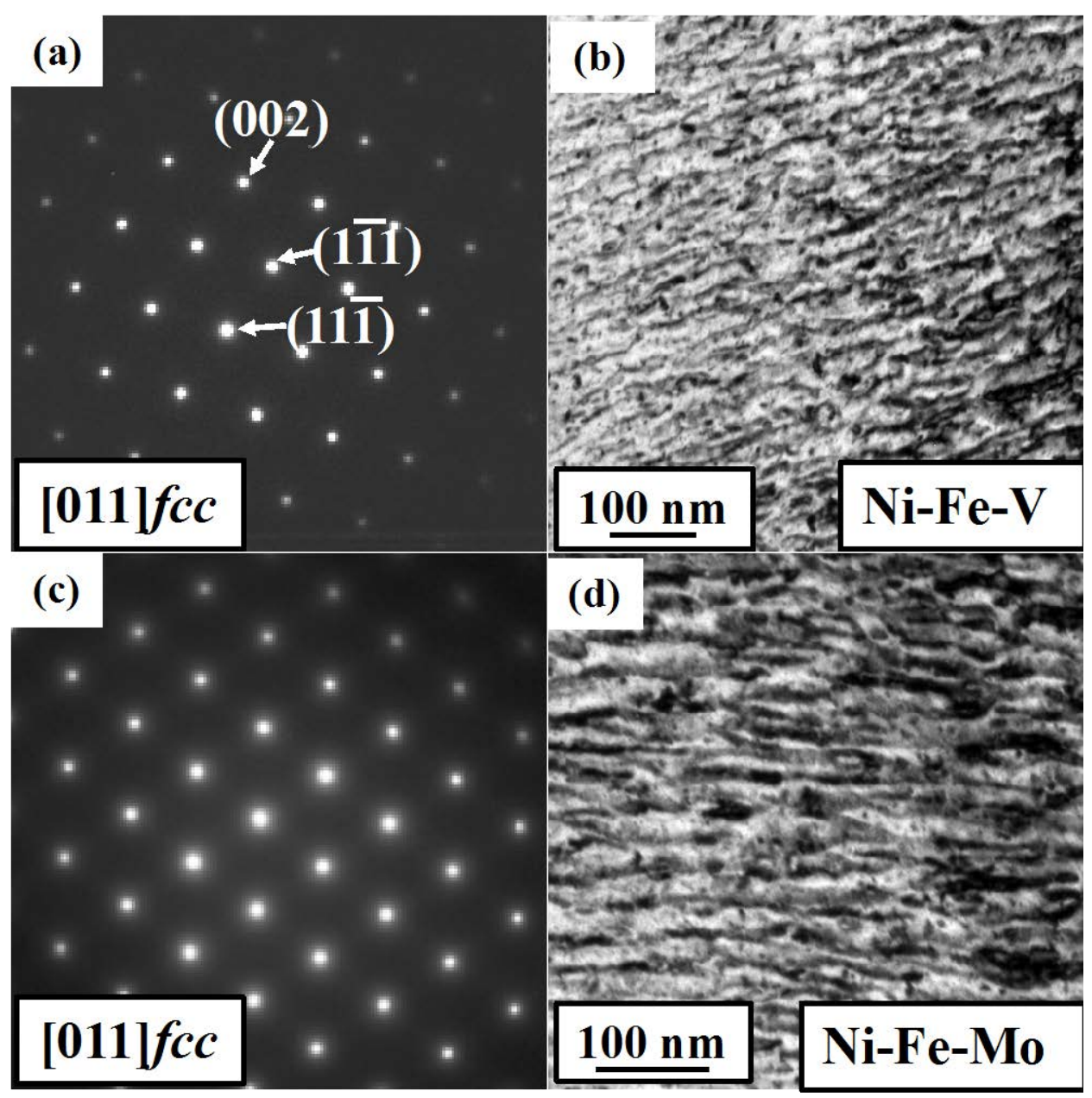

Figure 4.3: Selected area diffraction pattern and bright field TEM images of $\mathrm{Ni}-\mathrm{Fe}-\mathrm{V}(\mathrm{a}, \mathrm{b})$ and $\mathrm{Ni}-\mathrm{Fe}-\mathrm{Mo}(\mathrm{c}, \mathrm{d})$ alloys, respectively 
This image was recorded using a two-beam condition with $g=(200)$ excited near the [011] zone axis. Strain contrast consisted of near-regularly spaced striations with intervals of $15-20 \mathrm{~nm}$. This contrast is aligned along the $\{200\}$ planes of the $f c c$ matrix. This strain contrast could be related to a phase separating tendency within the fcc matrix. A [011] zone electron diffraction pattern and a $g=(200)$ two-beam bright-field TEM image from the Ni-Fe-Mo sample are shown in Figs. 4.3 (c) and (d), respectively. Both the diffraction pattern and the bright-field image are similar to those observed in case of the Ni-Fe-V alloy. More detailed investigations are required to establish the origin of the striated patterns.

The magnetization (M-H) curves of both Ni-Fe-V and Ni-Fe-Mo deposited alloys are shown in Figs. 4.4 (a) and (b), respectively; both exhibit well-defined hysteresis loops.

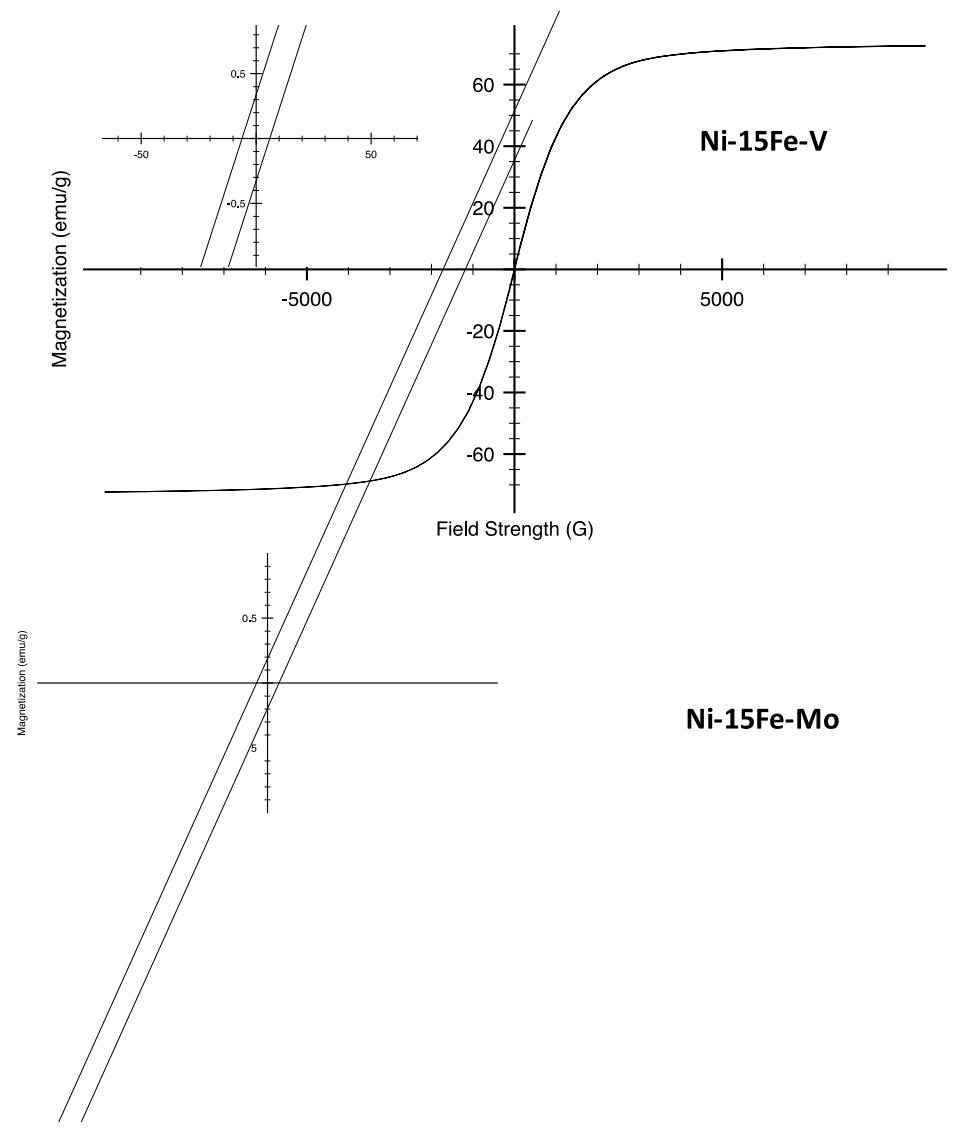

Figure 4.4: VSM magnetization curves for (a) deposited Ni-15Fe-V and (b) Ni-15Fe-Mo 
Saturation magnetization $\left(\mathrm{M}_{\mathrm{s}}\right)$ and coercivity $\left(\mathrm{H}_{\mathrm{c}}\right)$ values for the Ni-15Fe-5V sample are 72emu/g and 6.00e, respectively; while values for the Ni-15Fe-5Mo sample are $82 \mathrm{emu} / \mathrm{g}$ and 4.90e, respectively. The closest available composition in the literature, Ni-11Fe-6V, exhibits coercivity $\left(H_{c}\right)$ ranging between 0.0090 e to 0.030 , with saturation magnetization $\left(M_{s}\right)$ of approximately 50emu/g ${ }^{19}$. In case of $\mathrm{Ni}$-Fe-Mo Permalloy, the $\mathrm{H}_{\mathrm{c}}$ of $\mathrm{Ni}-17 \mathrm{Fe}-4 \mathrm{Mo}$ was between 0.0050 e to 0.030 , with an $M_{s}$ value of approximately $80 \mathrm{emu} / \mathrm{g}^{19,20}$. The larger coercivity and saturation magnetization in our laser-processed permalloys (Ni-15Fe-5V and Ni-15Fe-5Mo) compared to conventional permalloys ( $\mathrm{Ni}-11 \mathrm{Fe}-6 \mathrm{~V}$ and $\mathrm{Ni}-17 \mathrm{Fe}-4 \mathrm{Mo}$ ) may be due to their distinct material composition, since magnetic properties depend strongly on composition. The higher coercivity values in our LENS ${ }^{\mathrm{TM}}$ deposited alloys can be attributed to microstructural defects such as fine-scale porosity, un-melted particles, and other impurities. Nonetheless, the combination of $M_{s}$ and $H_{c}$ values exhibited by these samples make them promising candidates for soft magnetic applications. The ability to process these permalloys in near-net shape form in 3D geometries via AM processes can be highly advantageous when translating complex designs to novel components efficiently and potentially reproducibly.

\section{Conclusions}

Using laser engineered net shaping (LENS ${ }^{\mathrm{TM}}$ ), soft magnetic alloys based on $\mathrm{Ni}-\mathrm{Fe}-\mathrm{V}$ and Ni-Fe-Mo were successfully deposited from a blend of elemental powders. While the saturation magnetization of these alloys is comparable to conventionally processed versions of similar composition, the coercivities were higher for the laser-processed alloys. The microstructure and magnetic properties of these AM-processed alloys are promising for magnetic applications, 
especially considering the ability to process them in near-net shape form. Potential applications of such AM processed magnetic materials would be in transformers, electric motors, inductive, and other electromagnetic devices that require complex geometries.

\section{References}

1. Ripka, P. Sensors based on bulk soft magnetic materials: Advances and challenges. J. Magn. Magn. Mater. 320, 2466-2473 (2008).

2. Bas, J. ., Calero, J. . \& Dougan, M. . Sintered soft magnetic materials. Properties and applications. J. Magn. Magn. Mater. 254-255, 391-398 (2003).

3. Raposo, V. et al. Ferromagnetic resonance in low interacting permalloy nanowire arrays. J. Appl. Phys. 119, 143903 (2016).

4. Zhang, B., Fenineche, N.E., Zhu, L., Liao, H. \& Coddet, C. Studies of magnetic properties of permalloy (Fe30\%Ni) prepared by SLM technology. J. Magn. Magn. Mater. 324, 495500 (2012).

5. Abshinova, M. Factors Affecting Magnetic Properties of Fe-Si-Al and Ni-Fe-Mo Alloys. Procedia Eng. 76, 35-44 (2014).

6. Hirohata, A. et al. Heusler alloys in magnetic recording. in Heusler alloys in magnetic recording 82-86 (2014).

7. Yang, H. et al. Static and Dynamic Magnetization of Gradient FeNi Alloy Nanowire. Sci. Rep. 6, 20427 (2016).

8. Iron Systems, Part 5. 11D5, (Springer Berlin Heidelberg, 2009).

9. Hrabec, A. et al. Spin-orbit interaction enhancement in permalloy thin films by Pt doping. Phys. Rev. B 93, 14432 (2016).

10. Arnold, H.D. \& Elmen, G.W. Permalloy, A New Magnetic Material of Very High Permeability. Bell Syst. Tech. J. 2, 101-111 (1923).

11. Ustinovshchikov, Y.I., Shabanova, I.N. \& Lomova, N.V. Microstructures responsible for the invar and permalloy effects in Fe-Ni alloys. Russ. Metall. 2015, 389-394 (2015).

12. Zhang, Z.S., Yang, L., Yang, C.S. \& Cai, B.C. Effect of sputtering parameters on the magnetic properties of Mo-Permalloy. J. Appl. Phys. 64, 5670-5672 (1988). 
13. Murmu, P.P. et al. Synthesis and Compositional Analysis of Permalloy Powder Prepared by Arc-Discharge. J. Nanosci. Nanotechnol. 15, 9612-9616 (2015).

14. Chaudhary, V., Maheswar Repaka, D.V., Chaturvedi, A., Sridhar, I. \& Ramanujan, R.V. Magnetocaloric properties and critical behavior of high relative cooling power FeNiB nanoparticles. J. Appl. Phys. 116, 163918 (2014).

15. Chaudhary, V. \& Ramanujan, R.V. Magnetic and structural properties of high relative cooling power (Fe 70 Ni 30 ) 92 Mn 8 magnetocaloric nanoparticles. J. Phys. D. Appl. Phys. 48, 305003 (2015).

16. Chaudhary, V., Chaturvedi, A., Sridhar, I. \& Ramanujan, R.V. Fe\&amp;\#x2013;Ni\&amp;\#x2013;Mn Nanoparticles for Magnetic Cooling Near Room Temperature. IEEE Magn. Lett. 5, 1-4 (2014).

17. Ucar, H., Craven, M., Laughlin, D.E. \& McHenry, M.E. Effect of Mo Addition on Structure and Magnetocaloric Effect in $\mathrm{\gamma}$-FeNi Nanocrystals. J. Electron. Mater. 43, 137-141 (2014).

18. Qin, G.W. et al. Effect of Annealing on Magnetic Properties of Ni80Fe20 Permalloy Nanoparticles Prepared by Polyol Method. J. Nanosci. Nanotechnol. 11, 10796-10799 (2011).

19. Sato, Y. \& Takeyama, T. Magnetic and Mechanical Properties of a $6 \% \mathrm{~V}$ Permalloy as Magnetic Head Materials.

20. No Title. at <http://www.magneticmetals.com/> 


\section{CHAPTER 5}

\section{A COMBINATORIAL APPROACH FOR ASSESSING THE MAGNETIC PROPERTIES OF HIGH ENTROPY}

\section{ALLOYS: ROLE OF Cr IN AICoxCr ${ }_{1-x} \mathrm{FeNi}^{*}$}

The high entropy alloy field focuses mainly on microstructure and mechanical performance, while systematic work on the understanding of physical properties, especially magnetic properties, is still limited ${ }^{1-10}$. High entropy alloys based on the AlCoCrFeNi system and focusing on their microstructure, mechanical, anticorrosive, thermal, electrical and magnetic properties have been widely investigated. However, these previous reports typically concentrate on the influence of varying $\mathrm{Al}$ content in $\mathrm{Al}_{\mathrm{x}} \mathrm{CoCrFeNi}$ type compositions. Finetuning the microstructure and composition can substantially impact the magnetic properties and from this perspective, the contents of $\mathrm{Cr}$ and $\mathrm{Co}$ in this alloy system become critical ${ }^{11-13}$. Therefore, the need to understand the microstructural evolution and its effect on magnetic properties with varying $\mathrm{Co}$ and $\mathrm{Cr}$ content in $\mathrm{AlCo}_{x} \mathrm{Cr}_{1-\mathrm{x}} \mathrm{FeNi}$ type alloys is definite. Additionally, worth noting is that most of the commercially used hard magnets are based on systems such as AlNiCo or FeCrCo, and the soft magnets are based on NiFe, FeSi or FeCo.

Zhang et al. studied the structural and magnetic properties of FeCoNi(AISi)x $(0 \leq x \leq 0.8)$ high-entropy alloys ${ }^{14}$. They reported structural transition from FCC for $x \leq 0.2$ to BCC for $x \geq 0.4$, while a mix phase of FCC and BCC was observed in $0 \leq x<0.4$. The structural change from single FCC phase to single BCC phase with a transition duplex $\mathrm{FCC} / \mathrm{BCC}$ region has also been reported with increasing $x$ in $\mathrm{Al}_{x} \mathrm{CoCrFeNi}(0 \leq x \leq 2) \mathrm{HEAs}^{15}$. In FeNiCrCuCo HEAs, if Cu or Co was replaced

\footnotetext{
* Adapted from Borkar, T et al. A Combinatorial Approach for Assessing the Magnetic Properties of High Entropy Alloys: Role of $\mathrm{Cr}$ in $\mathrm{AlCO}_{x} \mathrm{Cr}_{1-\mathrm{x}} \mathrm{FeNi}$. Adv. Eng. Mater. Accepted (2017). Reproduced with permission from John Wiley \& Sons, Inc.
} 
by $\mathrm{Al}$, the microstructures changed from FCC solid solution to $\mathrm{BCC}$ solid solution ${ }^{16}$. The FCC-BCC transition with changing composition is normal in HEAs and can be explained by valence electron concentration and lattice distortion ${ }^{17,18}$. Phase stability is very important for control of the mechanical, electrical and magnetic properties of these HEAs.

The main objective of the present study is to study the effect of $\mathrm{Co} / \mathrm{Cr}$ ratio on the microstructure and magnetic properties of $\mathrm{AlCo}_{x} \mathrm{Cr}_{1-\mathrm{x}} \mathrm{FeNi}$ high entropy alloys. The systematic variation in composition was achieved via laser deposition of a compositionally graded alloy. Such a combinatorial approach permits the investigation of multiple compositional steps relatively quickly, yet systematically; and leads to new insights related to the evolution of microstructure and its consequent influence on the magnetic properties in such complex, concentrated multi-component systems.

\section{Experimental Procedure}

The compositionally graded alloys were deposited using LENS ${ }^{\mathrm{TM}}$ (Laser Engineered Net shaping) process. A $500 \mathrm{~W} \mathrm{Nd}$ :YAG laser, with spot size of $0.5 \mathrm{~mm}$, was used for all depositions. Oxygen content in the glove box was maintained below 10 ppm to avoid contamination. AlCoCrFeNi alloys with varying $\mathrm{Co} / \mathrm{Cr}$ ratios were deposited using a double powder feeder arrangement, AlCoFeNi (in one powder feeder) and AlCrFeNi (in second powder feeder). Composition variation was achieved by varying powder flow rate from both powder feeders during deposition. The compositionally graded sample exhibits a cylindrical geometry (10 mm diameter $\times 25 \mathrm{~mm}$ height). The powders used for depositing these alloys consisted of 
commercial near-spherical Al, Co, Cr, Fe, and Ni powders (purity at least $>99 \%$ ) with particle sizes in the range of $40-150 \mu \mathrm{m}$.

\section{Results and Discussion}

The composition gradient in the as-deposited $\mathrm{AlCo}_{x} \mathrm{Cr}_{1-\mathrm{x}} \mathrm{FeNi}$ graded alloy is schematically shown in Fig. 5.1, together with composition profiles for $\mathrm{Al}, \mathrm{Fe}, \mathrm{Co}, \mathrm{Cr}$, and $\mathrm{Ni}$ based on SEM-EDS measurements.
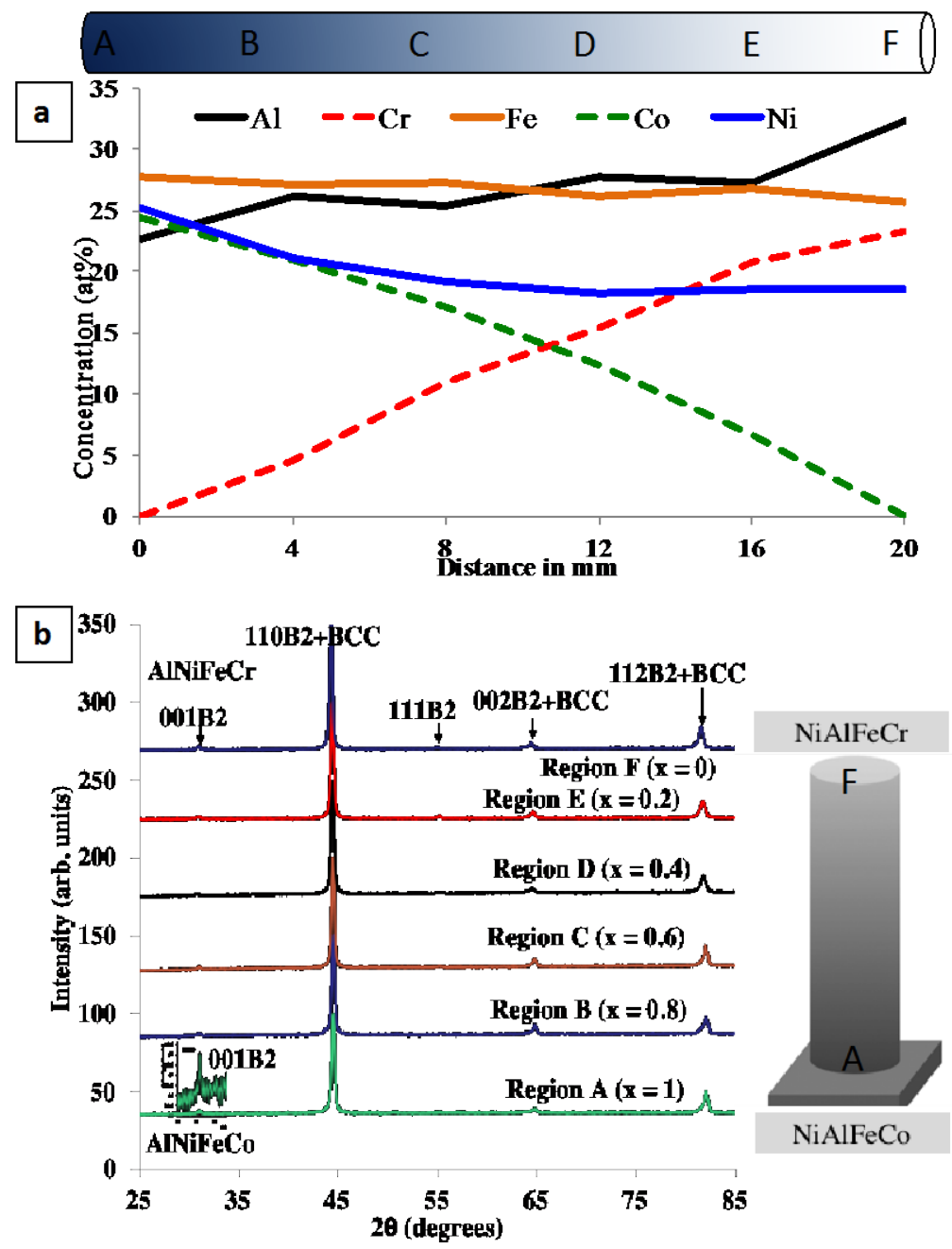

Figure 5.1: (a) Composition gradient in the as-deposited $\mathrm{AlCo}_{x} \mathrm{Cr}_{1-\mathrm{x}} \mathrm{FeNi}$ graded alloy, based on SEM-EDS measurements (b) XRD patterns from site specific locations (compositions) along the LENS $^{\mathrm{TM}}$ deposited $\mathrm{AlCo}_{\mathrm{x}} \mathrm{Cr}_{1-\mathrm{x}} \mathrm{FeNi}$ graded alloy 
For convenience of analysis, the entire graded alloy has been divided into six distinct composition steps, A, B, C, D, E, and F, corresponding to average compositions of $x=1,0.8,0.6$, $0.4,0.2$, and 0 . The average compositions of these regions are listed in Table $1 . \mathrm{The} \mathrm{Cr}$ at\% varies from 0 to 24 and Co at\% varies from 24 to 0 ; the compositions of the remaining elements (Al, $\mathrm{Fe}$, and $\mathrm{Ni}$ ) were kept nominally equiatomic. The measured compositions are quite close to the targeted values. XRD patterns from site-specific locations (compositions) along the LENS ${ }^{\mathrm{TM}}$ deposited $\mathrm{AlCO}_{x} \mathrm{Cr}_{1-\mathrm{x}} \mathrm{FeNi}$ graded alloy are shown in Fig. 5.1 (b). The principal peaks in all the XRD patterns have been indexed consistently as the $\{011\} b c c,\{002\} b c c$, and $\{112\} b c c$ peaks, with a strong $\{011\} b c c$ texture. Additionally, a peak is observed in the XRD patterns from all the regions, at $2 \theta$ of $\sim 30^{\circ}$; this peak can be indexed as the $\{001\}$ superlattice peak of an ordered B2 phase. Therefore, XRD patterns lead to the conclusion that for all alloy compositions investigated, $x=1$ to $x=0$, there is at least one ordered $B 2$ phase, and possibly a mixture of ordered B2 and disordered bcc phases.

The microstructure of the six different selected regions $(x=1,0.8,0.6,0.4,0.2$, and 0$)$ of the graded $\mathrm{AlCo}_{x} \mathrm{Cr}_{1-\mathrm{x}} \mathrm{FeNi}$ alloy is shown in the montage of backscattered SEM images in Fig. 5.2. At $x=1$ (i.e., nominal composition $\mathrm{AlCoFeNi}$ ), the microstructure shows equiaxed grains of a single $\mathrm{B} 2 / \mathrm{bcc}$ phase (lower magnification image on top and higher magnification image at the bottom). For $x=0.8$, while the primary grain structure appears to be similar to that of region $\mathrm{x}=1.0$, second phase precipitation was observed at the $\mathrm{B} 2 / \mathrm{bcc}$ grain boundaries. This grain boundary phase with a substantially brighter contrast in the backscatter SEM image indicates that the average atomic mass of this phase is greater than that of the $\mathrm{B} 2 / \mathrm{bcc}$ phase comprising the equiaxed grains. 


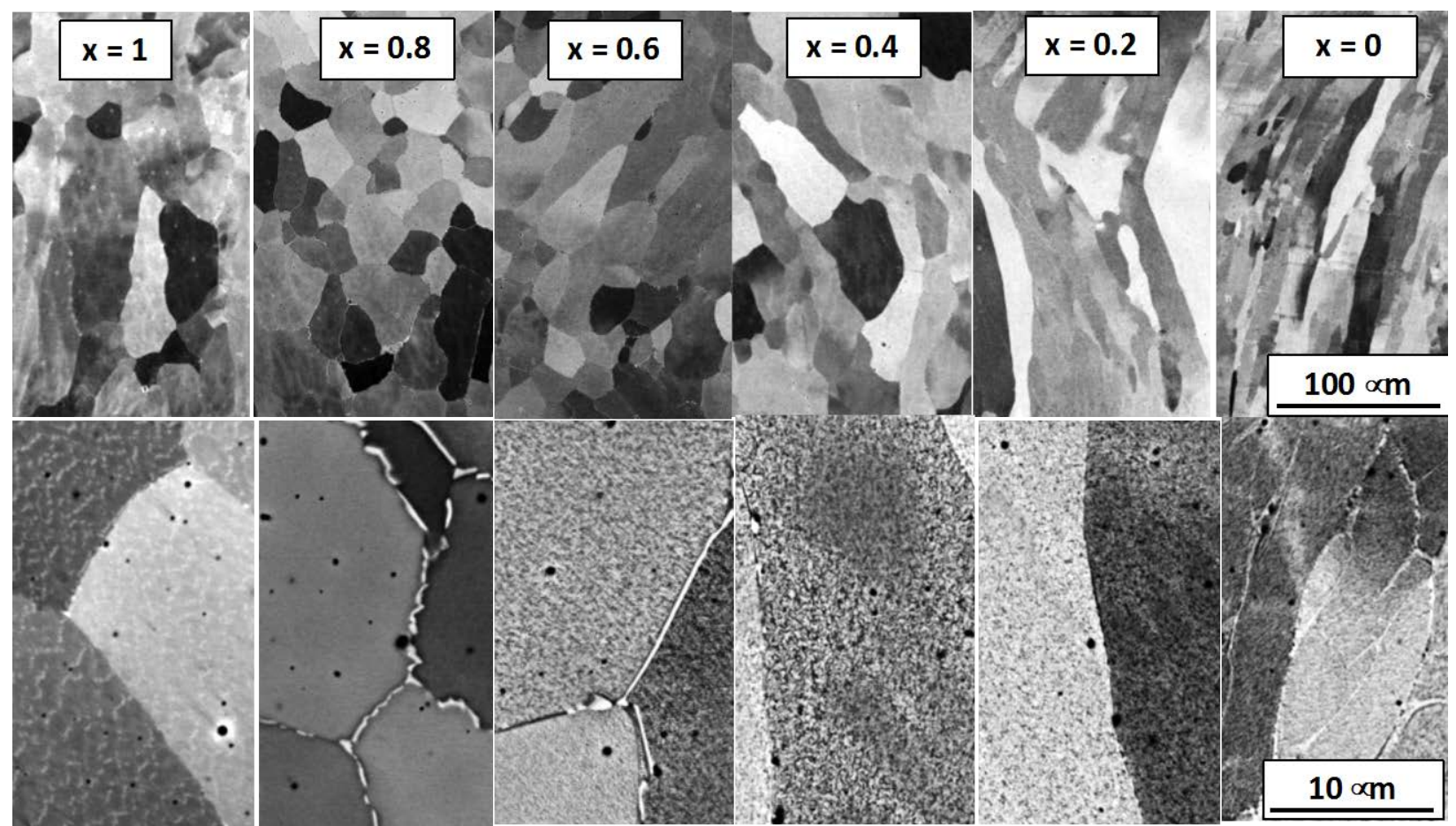

Figure 5.2: Backscattered SEM microstructure of the six different selected regions $(x=1,0.8,0.6$, $0.4,0.2$, and 0 ) of the graded $\mathrm{AlCo}_{x} \mathrm{Cr}_{1-\mathrm{x}} \mathrm{FeNi}$ alloy

For $\mathrm{x}=0.6$, although the equiaxed grains of the $\mathrm{B} 2 / \mathrm{bcc}$ phase exhibit a fine substructure, the higher atomic mass grain boundary phase remains. The region corresponding to $x=0.4$ exhibits fine-scale decomposition within the B2/bcc grains, similar to that the in case of $x=0.6$. However, the grain boundary phase no longer appears in the case of $x=0.4$. Regions corresponding to $\mathrm{x}=0.2$ and $\mathrm{x}=0$ exhibit similar microstructures, with the primary $\mathrm{B} 2 / \mathrm{bcc}$ grains exhibiting fine scale intra-granular decomposition. However, no other second phase was observed in either of these regions in the higher magnification backscatter SEM images. Interestingly, the fine scale intra-granular decomposition pattern observed in the case of regions $x=0.6,0.4,0.2$, and 0 , appears like a spinodal decomposition within the $B 2 / b c c$ grains. However, this can be confirmed only via investigations at higher resolution. Furthermore, the tendency for intra-granular decomposition appears to become more prominent with increasing 
$\mathrm{Cr}$ content and reducing Co content in this graded alloy. These SEM observations motivated further detailed TEM and APT investigations of specific regions in the graded $\mathrm{AlCo}_{\mathrm{x}} \mathrm{Cr}_{1-\mathrm{x}} \mathrm{FeNi}$ alloy. A more detailed investigation of the microstructure for the region corresponding to $x=1.0$ (AlFeNiCo) is shown in Fig. 5.3.
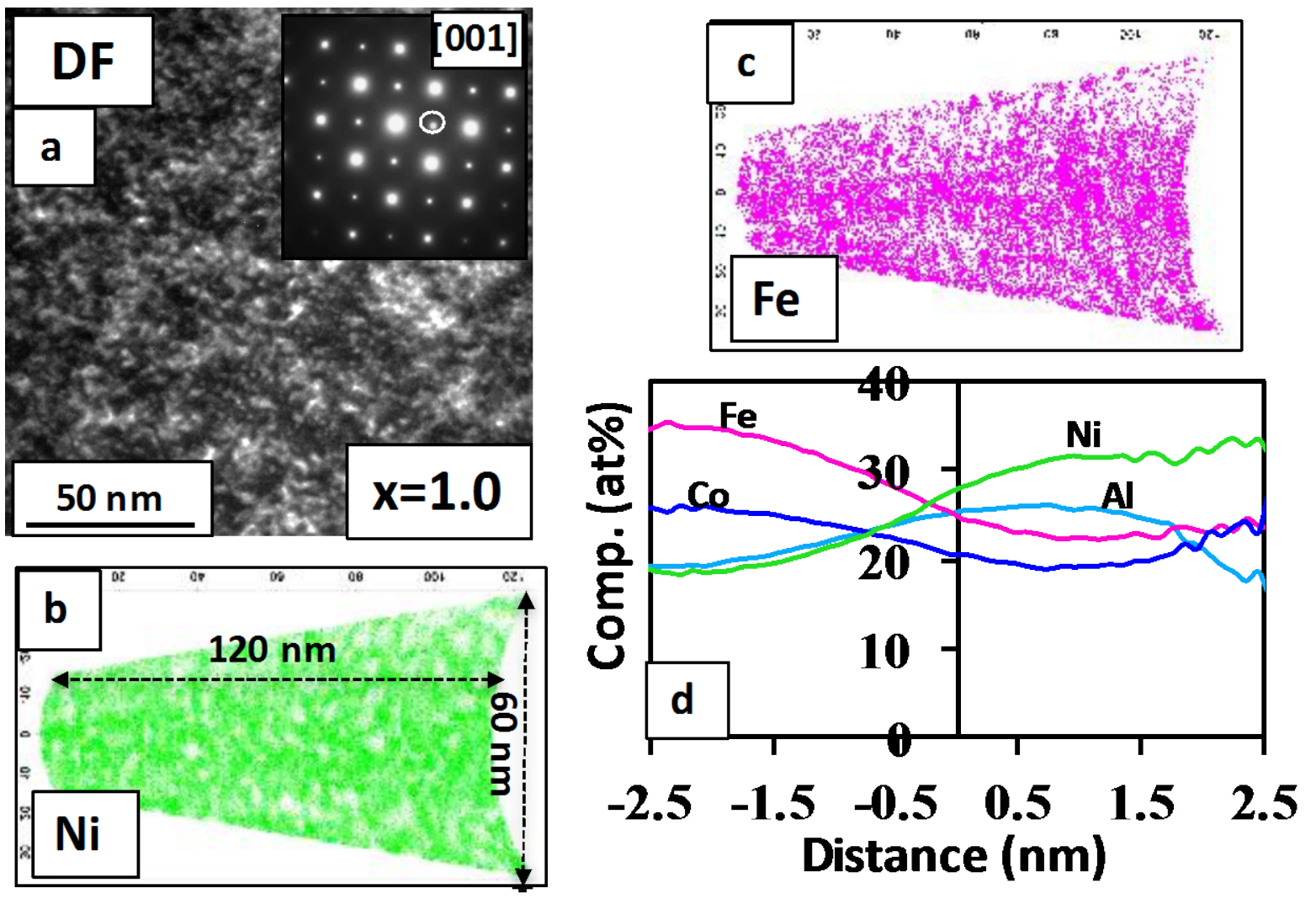

Figure 5.3: TEM and APT from $x=1.0$ in a AlCo ${ }_{x} \mathrm{Cr}_{1-\mathrm{x}} \mathrm{FeNi}$ alloy. (a) dark-field TEM image from within a grain together with the corresponding selected area diffraction (SAD) pattern (inset), (b) and (c) show the ionic 3D reconstructions of $\mathrm{Ni}$ and Fe atoms respectively, within an entire atom probe specimen from this region (d) proximity histogram profiles for $\mathrm{Ni}, \mathrm{Fe}, \mathrm{Al}$, and $\mathrm{Co}$ clearly revealing partitioning between $\mathrm{Ni}+\mathrm{Al}$ rich and $\mathrm{Fe}+\mathrm{Co}$ rich regions

A dark-field TEM image from within a grain together with the corresponding selected area diffraction (SAD) pattern (inset) from this region are shown in Fig. 5.3 (a). The electron diffraction pattern can be indexed consistently as the [001] zone axis of a B2 phase, exhibiting both the fundamental $b c c$ reflections as well as the $\{001\}$ superlattice reflections that arise from 
B2 ordering. The dark-field image was recorded from one of the $\{001\}$ superlattice reflections. While there appears to be a speckled contrast within this dark-field TEM image (Fig. 5.3 (a)), attributing this diffraction contrast to phase separation within the grains is difficult, since foil damage during ion-beam thinning of TEM foils can sometimes lead to such speckled contrast. Further investigation of the same composition region of $x=1.0$ was carried out using APT (Figs. 5.3 (b), (c), and (d)). Figs. 5.3 (b) and (c) show the atomic/ionic 3D reconstructions of $\mathrm{Ni}$ and Fe atoms, respectively, within an entire atom probe specimen. These raw ion maps clearly exhibit nanoscale compositional partitioning. A more robust quantitative analysis of the compositional partitioning observed in these APT reconstructions was carried out by constructing isoconcentration surfaces (isosurfaces) for 25 at $\% \mathrm{Ni}$ (delineating Ni-rich regions) and using these isosurfaces to plot proximity histogram profiles (or proxigram composition profiles) for $\mathrm{Ni}, \mathrm{Fe}$, $\mathrm{Al}$, and $\mathrm{Co}$. These proxigram profiles clearly reveal partitioning between $\mathrm{Ni}+\mathrm{Al}$ rich and $\mathrm{Fe}+\mathrm{Co}$ rich regions; compositional difference between the enriched and depleted regions is $~ 10$ at $\%$ for all the elements (Fig. 5.3 (d)).

A dark-field TEM image and the corresponding SAD pattern (inset) from the $x=0.8$ region are shown in Fig. 5.4 (a). In this case, the SAD pattern can be indexed consistently as the [011] zone axis of a B2 phase. However, the $\{001\}$ superlattice dark-field TEM image highlights an ordered B2 matrix where a high number density of darker pockets is not ordered. Hence, in the $\mathrm{x}=0.8$ case, the matrix grains have a mixed $\mathrm{B} 2+b c c$ microstructure and exhibit early stages of phase separation, presumably via spinodal decomposition. 

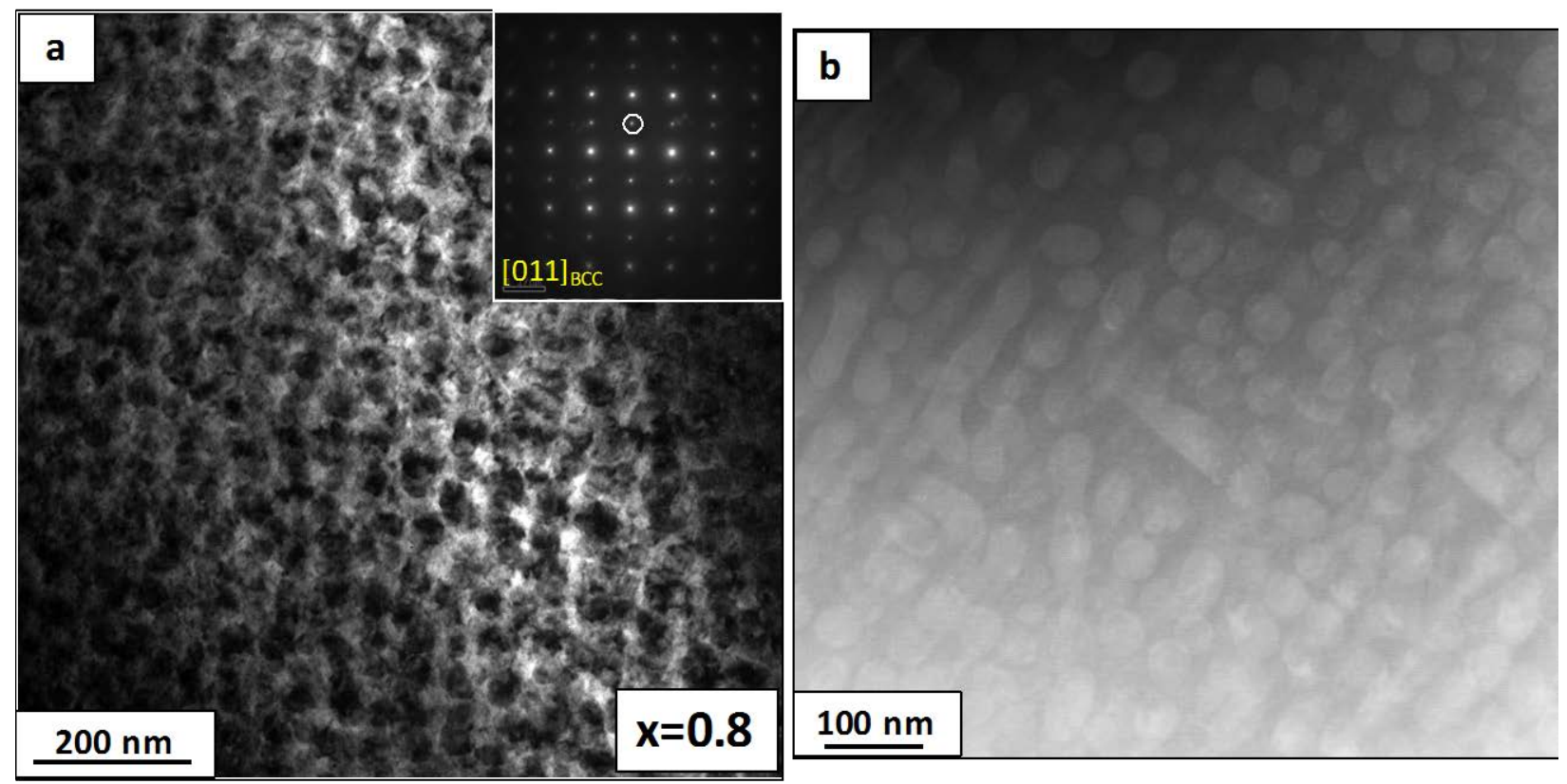

Figure 5.4: TEM from the $\mathrm{x}=0.8$ in a $\mathrm{AlCo}_{\mathrm{x}} \mathrm{Cr}_{1-\mathrm{x}} \mathrm{FeNi}$ alloy. (a) dark-field TEM image and the corresponding SAD pattern (inset), (b) the high angle annular dark-field (HAADF) - scanning transmission electron microscopy (STEM) image of the same microstructure.

This is further confirmed by the high angle annular dark-field (HAADF) - scanning transmission electron microscopy (STEM) image of the same microstructure shown in Fig. 5.4 (b). The contrast in this image can be attributed to atomic mass contrast, and confirms the early stages of phase separation into brighter contrast (heavier) disordered bcc pockets uniformly distributed within a darker contrast ordered B2 matrix. The spatial distribution of the $\mathrm{B} 2+b c c$ microstructure indicates a spinodal decomposition occurring within the matrix grains. Additionally, since the $x=0.8$ region also exhibited a grain boundary phase (Fig. 5.2 ), a sitespecific TEM sample was extracted from a grain boundary region of this composition. 

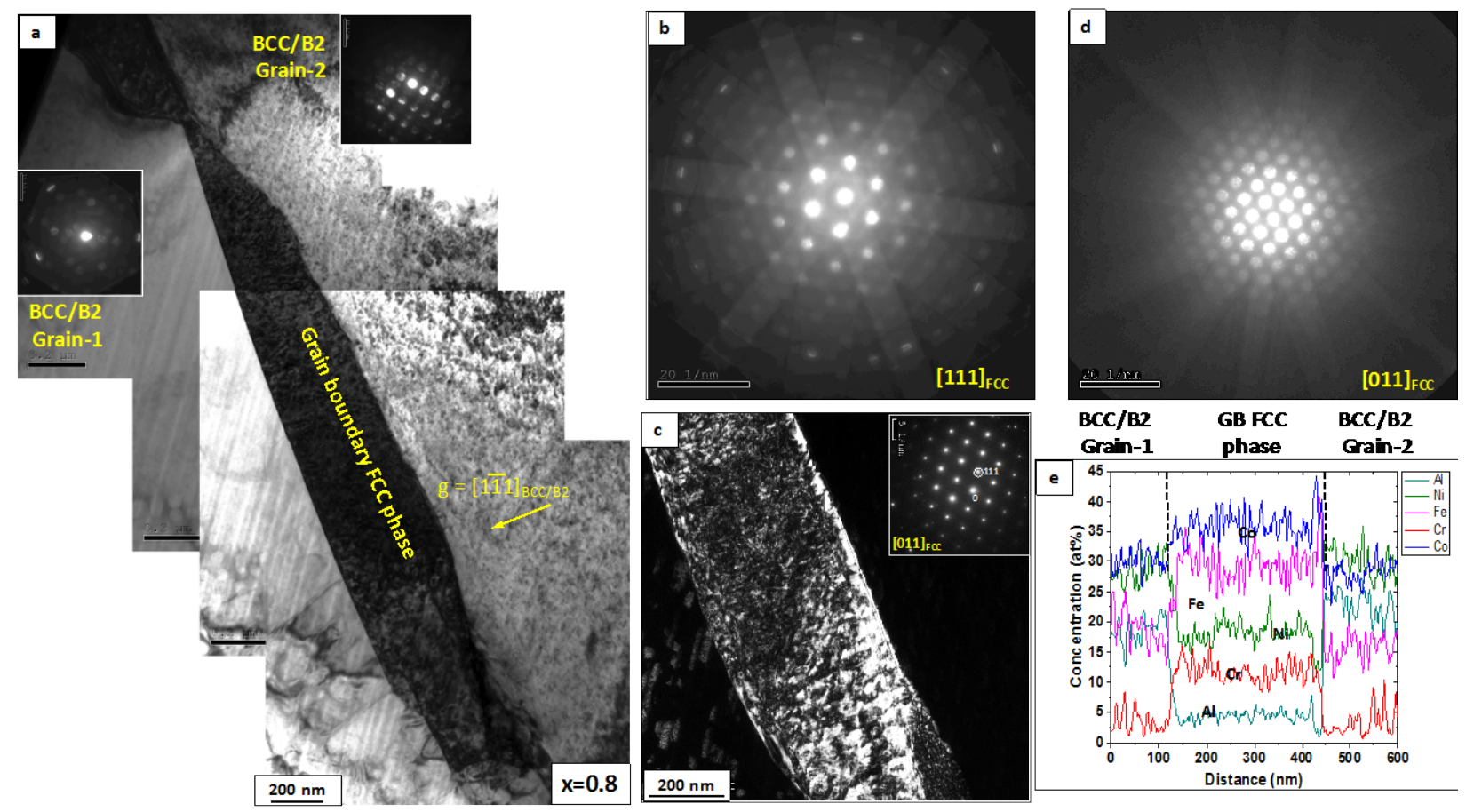

Figure 5.5: Grain boundary region TEM from the $\mathrm{x}=0.8$ in a $\mathrm{AlCo}_{\mathrm{x}} \mathrm{Cr}_{1-\mathrm{x}} \mathrm{FeNi}$ alloy. (a) Montage of bright-field TEM images, capturing one of these grain boundary precipitates, (b) dark-field image from the grain boundary precipitate, with the corresponding SAD patterns from [111]fcc and [110] fcc zone axis of the grain boundary precipitate respectively. (e) STEM-EDS composition profiles for $\mathrm{Ni}, \mathrm{Al}, \mathrm{Fe}, \mathrm{Co}$, and $\mathrm{Cr}$, recorded across the fcc grain boundary precipitate.

The montage of bright-field TEM images (Fig. 5.5 (a)) captures one of these grain boundary precipitates in a diffracting condition. The insets (Fig. 5.5 (a)) are micro-diffraction patterns corresponding to the two grains on either side of the grain boundary, and show clearly the misorientation between the grains. A dark-field image from the diffracting grain boundary precipitate shows the corresponding SAD pattern as an inset (Fig. 5.5 (c)). This SAD pattern can be indexed as the [011] zone axis of an fcc phase. Additionally, the [111] and [011] microdiffraction patterns from the same precipitate confirm that the grain boundary precipitate is a disordered fcc phase (Figs. 5.5 (b) and (d)). STEM-EDS composition profiles for $\mathrm{Ni}, \mathrm{Al}, \mathrm{Fe}, \mathrm{Co}$, and $\mathrm{Cr}$, recorded across the $f c c$ grain boundary precipitate, are shown in Fig. 5.5 (e). Based on these 
composition profiles, the average composition of the grain boundary phase was determined to be $36 \mathrm{Co}-29 \mathrm{Fe}-19 \mathrm{Ni}-11 \mathrm{Cr}-5 \mathrm{Al}$ (at \%), while that of the $\mathrm{B} 2+b c \mathrm{c}$ grains was $29 \mathrm{Co}-18 \mathrm{Fe}-29 \mathrm{Ni}-4 \mathrm{Cr}$ 20Al (at \%).

A detailed TEM analysis of the region with composition $\mathrm{x}=0.4$ in the graded $\mathrm{AlCo}_{x} \mathrm{Cr}_{1}$ ${ }_{x} \mathrm{FeNi}$ alloy (Fig. 5.6) shows a dark-field TEM image recorded using a \{001\}B2 superlattice reflection along with the corresponding [011] zone axis diffraction pattern (Fig. 5.6 (a) inset). The matrix is ordered with uniformly distributed disordered bcc pockets. While this mixed $\mathrm{B} 2+b c c$ microstructure also resembles that of a spinodal decomposition within the matrix grains, note that the length scale of the decomposition in this case for $x=0.4$ is substantially coarser compared to that observed in the case of $x=0.8$. Figs. 5.6 (b)-(c) show STEM-EDS maps of Fe and $\mathrm{Ni}$, respectively. While Ni partitions strongly to the ordered B2 matrix, Fe partitions to the disordered bcc phase. Detailed APT analysis of the same region (Fig. 5.6 (d-g)) confirms the partitioning trends across the B2/bcc interface. Fig. 5.6 (d-f) shows 3D reconstructions of atoms/ions for all the elements together (e), as well as individual reconstructions for each of the elements, $\mathrm{Ni}(\mathrm{d})$ and $\mathrm{Fe}(\mathrm{f})$, as marked. The composition profiles have also been plotted in the form of proximity histograms across a 16 at \% $\mathrm{Cr}$ isosurface (Fig. 5.6 (g)). APT reconstructions for the individual elements evidence that while $\mathrm{Ni}, \mathrm{Al}$, and Co strongly partition to the B2 phase, $\mathrm{Fe}$ and $\mathrm{Cr}$ partition to the $b c c$ phase. Note that Co within the $b c c$ phase is substantial, as is Fe in the B2 phase. Based on the proxigram analysis, the average composition of the B2 phase was $16 \mathrm{Co}-13 \mathrm{Fe}-30 \mathrm{Ni}-1 \mathrm{Cr}-40 \mathrm{Al}(\mathrm{at} \%)$; while that of the bcc phase was $6 \mathrm{Co}-52 \mathrm{Fe}-$ $1 \mathrm{Ni}-36 \mathrm{Cr}-5 \mathrm{Al}$ (at\%). Therefore, the ordered $\mathrm{B} 2$ phase is enriched in $\mathrm{Al}, \mathrm{Ni}$, and $\mathrm{Co}$, while the disordered $b c c$ phase is enriched in $\mathrm{Fe}$ and $\mathrm{Cr}$. 


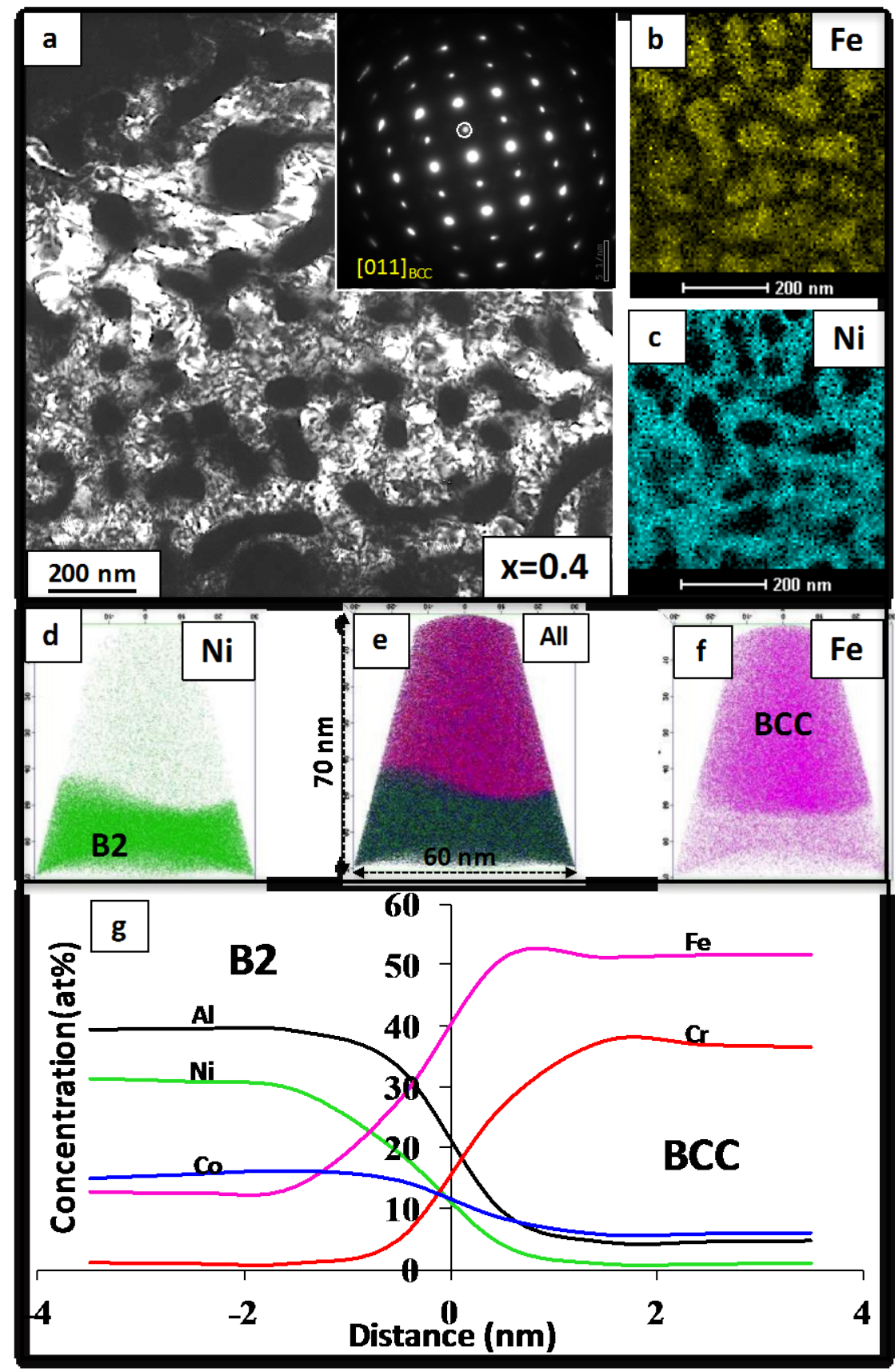

Figure 5.6: TEM and APT from the $x=0.4$ in a AlCo ${ }_{x} \mathrm{Cr}_{1-x}$ FeNi alloy. (a) dark-field TEM image from $\{001\} B 2$ superlattice reflection along with the corresponding [011] zone axis diffraction pattern shown as an inset. (b)-(c) show STEM-EDS maps of Fe and Ni, respectively. (d-f) shows 3D reconstructions of atoms/ions for all the elements together (e), as well as individual reconstructions for each of the elements, $\mathrm{Ni}(\mathrm{d})$ and $\mathrm{Fe}(\mathrm{f})$, as marked. (g) Composition profiles in the form of proximity histograms across a 16 at \% $\mathrm{Cr}$ isosurface

The B2 phase also contains a substantial amount of Fe. Interestingly, nanometer scale Fe-Cr rich clusters are seen within the $\mathrm{B} 2$ region, as revealed by the 3D atom probe reconstruction 
(supplementary Fig. S1 (a)). The compositions of these clusters have also been plotted in the same figure as 1D composition profiles, averaged over a cylinder of diameter $5 \mathrm{~nm}$, with the axes of these cylinders along the arrows marked I and II in Fig. S1 (b). These Fe-Cr rich clusters contain $\mathrm{Cr}$ amounts as high as 12-13 at\% in some cases, with the average content within the B2 phase being 1-2 at\%.

Finally, TEM and APT investigative results of the region corresponding to $x=0$ (AlFeNiCr) in the graded alloy are summarized in Fig. 5.7. The dark field image (Fig. 5.7 (a)) recorded using a $\{001\}$ superlattice B2 reflection in a $<001>$ zone axis SAD pattern (inset in Fig. 5.7(a)) clearly reveals a network of ordered B2 regions, mixed with a network of disordered bcc regions. The bright regions in the dark field image (Fig. 5.7(a)) correspond to the Ni-Al rich ordered BCC region, and darker regions correspond to the disordered Fe- $\mathrm{Cr}$ rich bcc region. This observation is consistent with the XRD and SEM analysis shown in Figs. 1 (b) and 2. A HAADF-STEM image of the same microstructure confirms the network structure as well as compositional partitioning between the two constituent phases (Fig. 5.7 (b)). This intermixed B2+bcc network indicates a spinodal decomposition within the grains (Figs. 5.7 (a) and (b)). APT reconstructions in 3D for $\mathrm{Ni}$, of atoms/ions for all the elements together and Fe, are shown in Figs. 5.7 (c), (d) and (e), respectively. An isosurface of 12 at\% $\mathrm{Cr}$ delineates the $\mathrm{B} 2$ and $b c c$ regions, and subsequently was used to construct proxigrams for all the elements involved (Fig. 5.7 (f)). The B2 regions exhibit a composition of $8 \mathrm{Fe}-44 \mathrm{Ni}-1 \mathrm{Cr}-47 \mathrm{Al}$ (at \%), while that of the bcc phase is $42 \mathrm{Fe}-1 \mathrm{Ni}-42 \mathrm{Cr}$ 15Al (at \%). Higher $\mathrm{Cr}$ content in AlFeNiCoCr alloys leads to distinct spinodal decomposition within the $\mathrm{BCC}$ grains. 


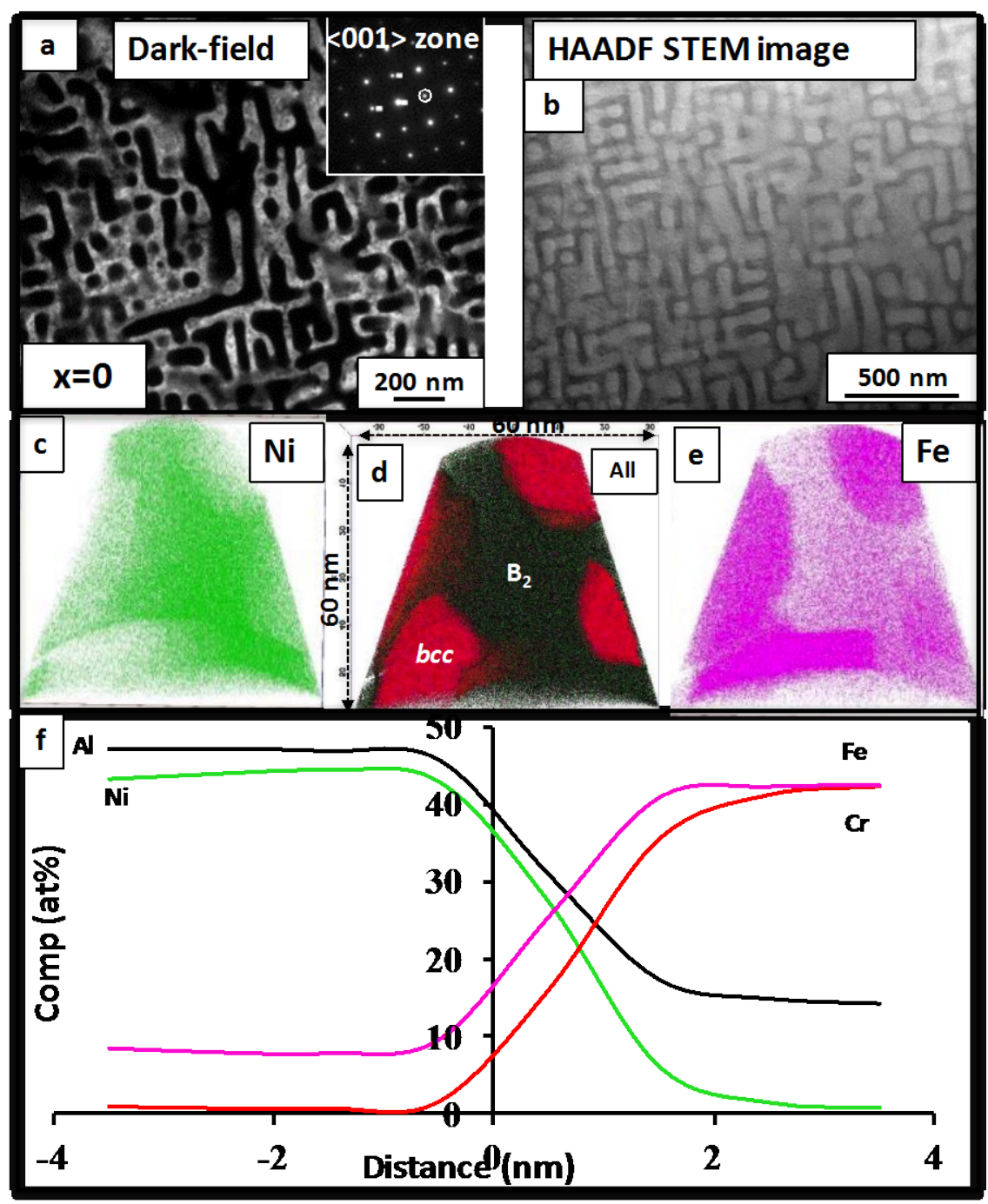

Figure 5.7: TEM and APT from the $\mathrm{x}=0$ in a $\mathrm{AlCo}_{\mathrm{x}} \mathrm{Cr}_{1-\mathrm{x}} \mathrm{FeNi}$ alloy. The dark field image from $\{001\}$ superlattice B2 reflection in a [001] zone axis diffraction pattern shown as an inset. (b) HAADFSTEM image of the same microstructure. (c-e) shows 3D reconstructions of atoms/ions for all the elements together (d), as well as individual reconstructions for each of the elements, Ni (c) and Fe (e), as marked. (f) Composition profiles in the form of proximity histograms across a 12 at $\% \mathrm{Cr}$ isosurface

Vibrating sample magnetometer results for the $\mathrm{LENS}^{\mathrm{TM}}$ deposited $\mathrm{AlCo}_{\mathrm{x}} \mathrm{Cr}_{1-\mathrm{x}} \mathrm{FeNi}$ alloys are displayed in Fig 8 as well as in Table 2. Fig. 8 (a) shows the hysteresis loops of the $\mathrm{AlCo}_{x} \mathrm{Cr}_{1-}$ ${ }_{x} \mathrm{FeNi}$ alloys. It is evident that the saturation magnetization $\left(\mathrm{M}_{\mathrm{s}}\right)$ decreases with increasing $\mathrm{Cr}$ content and correspondingly, the decrease in Co content. Co being the main element that 
contributes to ferromagnetism and $\mathrm{Cr}$ being antiferromagnetic in nature, the soft magnetic properties of $\mathrm{AlCo}_{x} \mathrm{Cr}_{1-\mathrm{x}} \mathrm{FeNi}$-based alloys are expected to decrease with increase in $\mathrm{Cr}$ content and corresponding decrease in Co content.
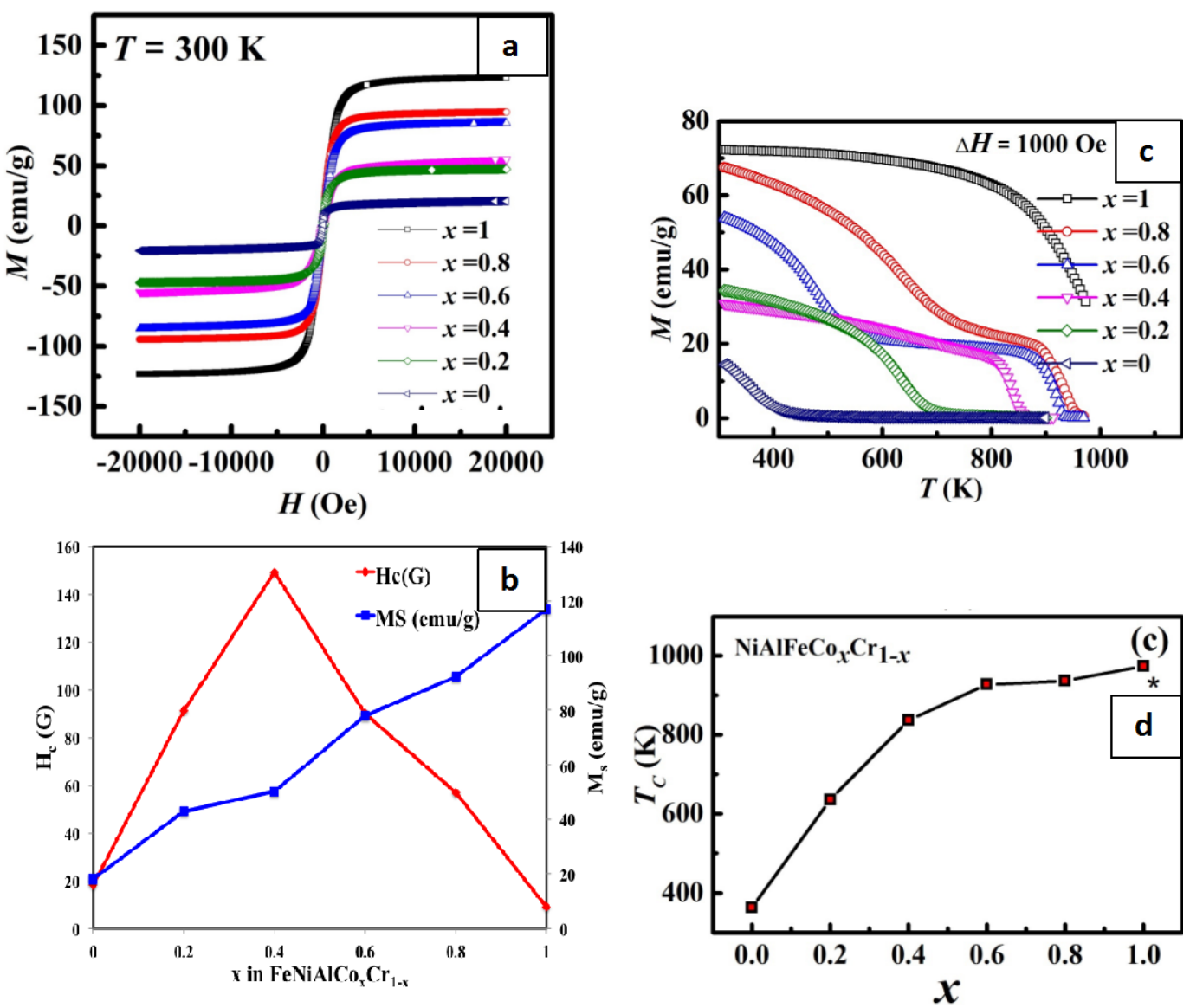

Figure 5.8: (a) Magnetizations (M) as a function of applied magnetic field $(\mathrm{H})$ at temperatures of $300 \mathrm{~K}$ for NiAlFeCoxCr1-x ( $\mathrm{x}=0,0.2,0.4,0.6,0.8$ and 1$)$; (b) show the saturation magnetizations (MS) and Coercivity ( $\mathrm{HC}$ ) as a function of Co concentration ( $\mathrm{X}=0$ to 1 ), respectively, at $300 \mathrm{~K}$. (c) Magnetization as a function of temperature at a magnetic field of $0.1 \mathrm{~T}$ in the temperature range from $\mathrm{RT}$ to $973 \mathrm{~K} \&$ (d) the variation of Curie temperature with the Co concentration in $\mathrm{NiAlFeCo} \mathrm{Cr}_{1-\mathrm{x}}(\mathrm{x}=0,0.2,0.4,0.6,0.8$ and 1$)$

Fig. 5.8 (a) shows the magnetic hysteresis loops obtained at $300 \mathrm{~K}$ for $\mathrm{AlCo}_{x} \mathrm{Cr}_{1-\mathrm{x}} \mathrm{FeNi}$ $(x=0,0.2,0.4,0.6,0.8$, and 1$)$. The hysteresis loops at $10 \mathrm{~K}$ can be seen in supplementary Fig. S2 (a). Figs. 5.8 (a) and S2 (b) show that at both these temperatures, the saturation magnetization $\left(M_{s}\right)$ increases on increasing $x$ from 0 to 1 . For all the $x$ values, $M_{s}$ is higher at $10 \mathrm{~K}$ as compared 
to $300 \mathrm{~K}$. The variations in $\mathrm{M}_{\mathrm{s}}$ and $\mathrm{H}_{\mathrm{c}}$, measured at $\mathrm{T}=300 \mathrm{~K}$, as a function of composition ( $\mathrm{x}$ ), are plotted in Fig. 5.8 (b). The saturation magnetization is determined primarily by the composition and atomic-level structures, and is less sensitive to microstructural parameters such as grain size and morphology. Indeed, saturation magnetization $\left(M_{s}\right)$ rises almost monotonically upon the addition of Co and corresponding reduction in $\mathrm{Cr}$, from $18.48 \mathrm{emu} / \mathrm{g}$ at $\mathrm{x}=0$ (AINiFeCr) all the way to $117.8 \mathrm{emu} / \mathrm{g}$ at $\mathrm{x}=1$ (AINiFeCo). In contrast, the composition dependence of $\mathrm{H}_{\mathrm{c}}$ appears to be non-monotonic: $\mathrm{H}_{\mathrm{c}}$ is low for $\mathrm{x}=0$, but increases dramatically at $\mathrm{x} \leq 0.4$ and then falls again for $x>0.4$, reaching a low value at $x=1$. This is due mainly to the increase in Co content and decrease in $\mathrm{Cr}$ content in these alloys. The addition of $\mathrm{Cr}$ significantly reduces magnetization because the magnetic moment of $\mathrm{Cr}$ is anti-parallel to that of $\mathrm{Fe} / \mathrm{Co} / \mathrm{Ni}$ (i.e., antiparallel magnetic coupling), and thus results in the reduction/cancellation of the magnetic moment in $\mathrm{Cr}$-containing HEAs. Li et al. reported a similar behavior in the alloy $\mathrm{Fe}_{3-x} \mathrm{Cr}_{x} \mathrm{Se}_{4}(\mathrm{x}=0$ to 2 ), where the coercivity is maximum at room temperature for $x=0.7$ and then decreases on both sides of $x$, as observed in the present case ${ }^{19}$. The non-magnetic component Al is nearly non-polarized (or slightly anti-parallel with $\mathrm{Fe} / \mathrm{Co} / \mathrm{Ni}$ ). Thus, $\mathrm{x}=1.0$ (AINiFeCo) exhibits the best soft magnetic properties as compared to other compositions in this system.

Fig. 5.8 (c) shows the temperature dependence from room temperature to $973 \mathrm{~K}$ of magnetization, $\mathrm{M}(\mathrm{T})$ of $\mathrm{AlCo}_{\mathrm{x}} \mathrm{Cr}_{1-\mathrm{x}} \mathrm{FeNi}(\mathrm{x}=0,0.2,0.4,0.6,0.8$ and 1$)$, under an applied field of 1000 Oe. The phase transition temperatures between the paramagnetic and ferromagnetic states (Curie temperature, $T_{c}$ ) were determined from the minima of the plot of $d M / d T$ versus $T$ (shown in supplementary Fig. S2 (b)). Fig. 5.8 (d) shows the change in $T_{c}$ with Co content (x). The $T_{C}$ for $x=1$ is equal to $973 \mathrm{~K}$, while for $x=0$, the $T_{C}$ is only $363 \mathrm{~K}$. The reduction of $T_{C}$ is 
consistent with the mean field model $T_{C}=J(r)_{\text {eff }} Z_{T} S(S+1) / 3 k_{B}$, where $J(r)_{\text {eff }}$ is the effective exchange interaction, $Z_{T}$ is coordination number, $S$ is the atomic spin quantum number and $k_{B}$ is the Boltzmann constant. $\mathrm{Cr}$ exhibits antiferromagnetic ordering, and therefore effective exchange interaction $\left(J(r)_{e f f}\right)$ decreases with increasing the $\mathrm{Cr}$ content in AlFeNiCo $\mathrm{Cr}_{1-x}$, which results in a reduction in $\mathrm{T}_{c}$. The $\mathrm{T}_{c}$ of the $\mathrm{Fe}_{74-x} \mathrm{Cr}_{x} \mathrm{Cu}_{1} \mathrm{Nb}_{3} \mathrm{Si}_{15.5} \mathrm{~B}_{6.5},\left(\mathrm{Fe}_{70} \mathrm{Ni}_{30}\right)_{1-x} \mathrm{Cr}_{x}$ and $\left(\mathrm{Fe}_{70} \mathrm{Ni}_{30}\right)_{1-}$ ${ }_{x} \mathrm{Mn}_{x}$ alloys also decreased with increasing $\mathrm{Cr}$ or $\mathrm{Mn}$ content in corresponding alloy ${ }^{20-23}$. On the other hand, Co substitution for Fe increases the $\mathrm{T}_{\mathrm{C}}$ with increasing $\mathrm{x}$ in $\mathrm{RE}_{2} \mathrm{Fe}_{14-\mathrm{x}} \mathrm{Co}_{x} \mathrm{~B}$ compounds. For $\mathrm{x}=0.6$ and 0.8 , two minima in the plots of $d M / d T$ versus $T$ (Fig. S2 (b)) suggest that these samples contain an additional magnetic phase exhibiting a second transition. These additional minima $\left(T_{C}^{\prime}\right)$ at $481 \mathrm{~K}$ for $\mathrm{x}=0.6$ and at $636 \mathrm{~K}$ for $\mathrm{x}=0.8$ are probably due to magnetic ordering of the fcc phase observed at the grain boundaries. TEM and SEM analyses confirmed that only these two samples $(x=0.6$ and $x=0.8)$ exhibit the grain boundary precipitate phase, a disordered $f c c$ phase. The $T_{C}{ }^{\prime}=481 \mathrm{~K}$ for $\mathrm{x}=0.6$ is less than that of $T_{C}{ }^{\prime}=636 \mathrm{~K}$ for $\mathrm{x}=8$ due to the more $\mathrm{Cr}$ content in the former.

Microstructural Evolution and Its Impact on Magnetization in $\mathrm{AlCo}_{x} \mathrm{Cr}_{1-x} \mathrm{FeNi}$ Combinatorial analysis of the compositionally graded $\mathrm{AlCo}_{x} \mathrm{Cr}_{1-\mathrm{x}} \mathrm{FeNi}$ alloy leads to the following observations regarding the microstructural evolution as a function of composition:

1. Over the entire range of compositions, from $x=0$ to 1 , the alloys exhibit a bcc-based microstructure consisting of the ordered B2 phase and a disordered bcc solid solution phase. 
2. The effect of decreasing Co content (decreasing $\mathrm{x}$ ), or increasing $\mathrm{Cr}$ content is a progressive tendency towards phase separation via spinodal decomposition within the bcc-based matrix grains to form a mixed two-phase B2+bcc microstructure. Thus, while $x=0$ (AlFeNiCo) exhibits grains of a single $B 2$ phase, $x=1$ (AlFeNiCr) exhibits pronounced spinodal decomposition within the matrix grains, and results in a patterned two-phase B2+bcc microstructure.

3. Specific compositions along the graded $\mathrm{AlCo}_{\mathrm{x}} \mathrm{Cr}_{1-\mathrm{x}} \mathrm{FeNi}$ alloy, $\mathrm{x}=0.8$ and $\mathrm{x}=0.6$, exhibit a second grain boundary precipitate phase, which is an $f c c$ solid solution.

The magnetization behavior and magnetic properties of different sections of the AlCo ${ }_{x} \mathrm{Cr}_{1-\mathrm{x}} \mathrm{FeNi}$ graded alloy vary substantially as a function of composition coupled with the microstructure. Thus, increasing the Co content from $x=0$ (AlCrFeNi) to $x=1$ (AICoFeNi) exhibits a monotonically increasing value of $\mathrm{M}_{\mathrm{s}}$, since saturation magnetization is strongly dependent on alloy composition, with lesser influences from the microstructure. In contrast, the variation in $\mathrm{H}_{\mathrm{c}}$ is highly non-monotonic and appears to be strongly influenced by the microstructure. Thus, while $H_{c}$ increases with increasing Co content from $x=0$ to $x=0.4$, the value drops quite steeply with increasing $x$ from $x=0.4$ to $x=1.0$. The decrease in $H_{c}$ from $x=0.4$ to $x=1.0$ is potentially attributable to the change in microstructure from a pronounced spinodally decomposed $B 2+b c c$ microstructure for $\mathrm{x}=0.4$, to a marginally phase separated $\mathrm{B} 2$ microstructure (with composition fluctuations) for $x=1.0$. Thus, the extent of spinodal decomposition within the matrix grains has potential influence on the pinning of magnetic domains and consequently on coercivity. The well-developed spinodally decomposed $\mathrm{B} 2+b c c$ microstructure in case of $\mathrm{x}=0.4$ can exhibit a higher coercivity due to the B2/bcc boundaries acting as pinning sites for the domains, while 
such boundaries do not exist within the large grains of the single B2 phase observed in case of $x=1.0$. Additionally, the substantial difference between the chemical compositions of the $B 2$ and $b c c$ phases at $\mathrm{x}=0.4$ presumably causes a difference in their respective lattice parameters; and the two phases accommodate this mismatch via coherency stresses that potentially stabilize the orientation of elementary magnetic domains imposed by an external magnetic field. Furthermore, spinodally decomposed microstructures have been used to design most modernday permanent magnets, including Fe-22Cr-12Co and AINiCo-based $12,13,24,25$. The anisotropy of the magnetic properties depends on the form of the elementary domains and can be modified by either annealing in a magnetic field, or via cold deformation.

However, the same rationale does not explain the behavior from $x=0$ to $x=0.4$, where the increase in coercivity is strong with increasing values of $x$; while a well-developed spinodally decomposed $\mathrm{B} 2+b c c$ microstructure is observed for all compositions within this range $(x=0,0.2$, and 0.4). Therefore, the rationale behind the substantial variation in $\mathrm{H}_{c}$ within this range of compositions needs further investigation. A noteworthy aspect is the substantial differences between the compositions of the B2 and bcc phases, comprising the spinodally decomposed microstructure, for $\mathrm{x}=0.4$ and $\mathrm{x}=0$. The compositions for the $\mathrm{B} 2$ and $b c c$ phases in case of $\mathrm{x}=0.4$ are $16 \mathrm{Co}-13 \mathrm{Fe}-30 \mathrm{Ni}-1 \mathrm{Cr}-40 \mathrm{Al}$ (at\%) and 6Co-52Fe-1 Ni-36Cr-5Al (at\%), respectively; while for $\mathrm{x}=0$, they are $8 \mathrm{Fe}-44 \mathrm{Ni}-1 \mathrm{Cr}-47 \mathrm{Al}$ (at\%) and 42Fe-1Ni-42Cr-15Al (at\%), respectively. Therefore, quite likely, the high Co content in the B2 phase for the $\mathrm{x}=0.4$ composition, is what causes the strongly ferromagnetic behavior 26,27; while the bcc phase in the same case is rather weakly ferromagnetic due to the high content of antiferromagnetic $\mathrm{Cr}$, as well as a lower Co content. Consequently, the difference in the magnetic moments of the B2 and bcc phase in case of the 
alloy of composition $\mathrm{x}=0.4$ could be substantial. This results in the $\mathrm{B} 2 / \mathrm{bcc}$ phase boundaries in the spinodally decomposed microstructure acting as effective pinning sites for the magnetic domains, consequently increasing the coercivity. However, in the case of the alloy of composition $\mathrm{x}=0$, AlCrFeNi, neither the $\mathrm{B} 2$ nor bcc phases contain any $\mathrm{Co}$; the $\mathrm{B} 2$ phase is primarily NiAl with a small amount of $\mathrm{Fe}$, while the $b c c$ phase is primarily $\mathrm{Fe}-\mathrm{Cr}$ (equal atomic percent) with 15 at\% of paramagnetic Al. Therefore, likely neither the B2 nor the bcc phases in this case exhibits a strong magnetic moment, and both are weakly ferromagnetic.

Consequently, the B2/bcc phase boundaries in this spinodally decomposed microstructure are not effective pinning sites for the magnetic domains, and the overall coercivity of the alloy is relatively low. Thus, addition of Co also is important to enhancing permanent magnetic behavior ${ }^{11}$. The composition dependence of $\mathrm{Hc}$ in $\mathrm{FeCoNi}(\mathrm{AlSi})_{x}$ and $\mathrm{Al}{ }_{x} \mathrm{CoCrFeNi} \mathrm{HEAs}$ was also irregular ${ }^{14,24}$. The Ms and Hc of the CoCrFeCuNi HEA were estimated to be $53.41 \mathrm{emu} / \mathrm{g}$ and 166 Oe, respectively ${ }^{28}$.

Regarding the $\mathrm{M}$ versus $\mathrm{T}$ behavior of the compositions along the graded $\mathrm{AlCo}_{x} \mathrm{Cr}_{1-x} \mathrm{FeNi}$ alloy, the primary paramagnetic-ferromagnetic phase transition temperature $\left(T_{c}\right)$ increases systematically with increasing Co content (increasing $\mathrm{x}$ ), and this can be rationalized based on the mean-field model, and was discussed earlier. Experimental results confirm that this phase transition temperature can be attributed to the $B 2 / b c c$ phase(s), the principal component of the microstructure for all compositions. Since for the compositions $x=0,0.2,0.4$, and 1.0 , the B2/bcc phase(s) are the only ones present, these compositions exhibit a single transition temperature $\left(T_{c}\right)$ in their M versus T plots (Figs. 8(c) and S2 (b)). However, for compositions $\mathrm{x}=0.6$ and $\mathrm{x}=0.8$, two distinct transition temperatures, $\mathrm{T}_{c}$ and $\mathrm{T}_{c}{ }^{1}$, occur. While the higher of 
these values, $T_{c}$, can be attributed to the $B 2 / b c c$ phase(s), the second lower value, $T_{c}{ }^{1}$, arises from a second paramagnetic to ferromagnetic transition, presumably in the $f c c$ phase observed at the grain boundaries for these two compositions. Similar observations of two magnetic phase transitions have been reported in other systems, such as FeNiB, FeCoCrNi, and FeCoCrNiAlCu alloys, and have been attributed either to magnetic ordering or the presence of an additional second phase in the parent structure ${ }^{2,29,30}$. However, note that any detailed characterization of the microstructure and phases present was absent in these previous reports.

\section{Conclusions}

The graded AlFeNiCo $\mathrm{Cr}_{1-\mathrm{x}}$ alloys ( $\mathrm{x}$ varying from 0 to 1 ) were deposited successfully using laser engineered net shaping (LENS ${ }^{\mathrm{TM}}$ ) technology. Not much change was observed in the phases formed in these alloys with varying $\mathrm{Co}$ and $\mathrm{Cr}$ content. All alloy compositions exhibited BCC and B2 (ordered BCC) phases. Region A corresponding to AINiFeCo alloys featured equiaxed morphology and shows early stages of phase separation into Ni-Al rich and Fe-Co rich regions. As $\mathrm{Cr}$ content increases, distinct spinodal decomposition was observed within BCC grains. Both TEM and APT analyses show that Region F corresponding to AINiFeCr alloys exhibits spinodal decomposition within BCC grains. Saturation magnetization (Ms) rises monotonically upon Co addition, from $18.48 \mathrm{emu} / \mathrm{g}$ at $\mathrm{x}=0$ (AINiFeCr) to $117.8 \mathrm{emu} / \mathrm{g}$ at $\mathrm{x}=1$ (AINiFeCo). Addition of $\mathrm{Cr}$ significantly reduces magnetization because the magnetic moment of $\mathrm{Cr}$ is antiparallel with $\mathrm{Fe} / \mathrm{Co} / \mathrm{Ni}$ (i.e., anti-parallel magnetic coupling). Combinatorial rapid assessment of 
novel magnetic alloys has been demonstrated using graded alloys deposited using laser additive processing.

\section{References}

1. Miracle, D. et al. Exploration and Development of High Entropy Alloys for Structural Applications. Entropy 16, 494-525 (2014).

2. Zhang, Y. et al. Microstructures and properties of high-entropy alloys. Prog. Mater. Sci. 61, 1-93 (2014).

3. Lucas, M.S. et al. Magnetic and vibrational properties of high-entropy alloys. J. Appl. Phys. 109, $07 \mathrm{E} 307$ (2011).

4. Osaka, T. et al. A soft magnetic CoNiFe film with high saturation magnetic flux density and low coercivity. Nature 392, 796-798 (1998).

5. Tsai, M.-H., Yeh, J.-W. \& Gan, J.-Y. Diffusion barrier properties of AlMoNbSiTaTiVZr highentropy alloy layer between copper and silicon. Thin Solid Films 516, 5527-5530 (2008).

6. Senkov, O.N., Wilks, G.B., Miracle, D.B., Chuang, C.P. \& Liaw, P.K. Refractory high-entropy alloys. Intermetallics 18, 1758-1765 (2010).

7. Huang, C., Zhang, Y., Shen, J. \& Vilar, R. Thermal stability and oxidation resistance of laser clad TiVCrAlSi high entropy alloy coatings on Ti-6Al-4V alloy. Surf. Coatings Technol. 206, 1389-1395 (2011).j

8. Chuang, M.-H., Tsai, M.-H., Wang, W.-R., Lin, S.-J. \& Yeh, J.-W. Microstructure and wear behavior of AlxC01.5CrFeNi1.5Tiy high-entropy alloys. Acta Mater. 59, 6308-6317 (2011).

9. Senkov, O.N., Scott, J.M., Senkova, S.V., Miracle, D.B. \& Woodward, C.F. Microstructure and room temperature properties of a high-entropy TaNbHfZrTi alloy. J. Alloys Compd. 509, 6043-6048 (2011).

10. Kuznetsov, A.V., Shaysultanov, D.G., Stepanov, N.D., Salishchev, G.A. \& Senkov, O.N. Tensile properties of an AlCrCuNiFeCo high-entropy alloy in as-cast and wrought conditions. Mater. Sci. Eng. A 533, 107-118 (2012).

11. MISHIMA, T. Strong permanent magnet with cobalt. (1936).

12. Zhang, L. Coercivity Enhancement and Gamma Phase Avoidance of Alnico Alloys. (University of Nebraska-Lincoln, 2016). 
13. Chin, T.-S., Wu, T.S., Chang, C.Y., Hsu, T.K. \& Chang, Y.H. Electron microscopy and magnetic properties of Fe-Cr-Co-Si permanent magnet alloys manufactured by rollingageing technique. J. Mater. Sci. 18, 1681-1688 (1983).

14. Zhang, Y., Zuo, T., Cheng, Y. \& Liaw, P.K. High-entropy Alloys with High Saturation Magnetization, Electrical Resistivity, and Malleability. Sci. Rep. 3, (2013).

15. Chou, H.-P., Chang, Y.-S., Chen, S.-K. \& Yeh, J.-W. Microstructure, thermophysical and electrical properties in AlxCoCrFeNi $(0 \leq x \leq 2)$ high-entropy alloys. Mater. Sci. Eng. B 163, 184-189 (2009).

16. Li, C., Li, J. C., Zhao, M. \& Jiang, Q. Effect of alloying elements on microstructure and properties of multiprincipal elements high-entropy alloys. J. Alloys Compd. 475, 752-757 (2009).

17. Guo, S., Ng, C., Lu, J. \& Liu, C.T. Effect of valence electron concentration on stability of fcc or bcc phase in high entropy alloys. J. Appl. Phys. 109, 103505 (2011).

18. Wang, F.J., Zhang, Y. \& Chen, G.L. Atomic packing efficiency and phase transition in a high entropy alloy. J. Alloys Compd. 478, 321-324 (2009).

19. Li, S., Li, D., Liu, W. \& Zhang, Z. High Curie temperature and coercivity performance of Fe 3-x Cr x Se 4 nanostructures. Nanoscale 7, 5395-5402 (2015).

20. Moreno-Ramírez, L.M. et al. Magnetocaloric response of amorphous and nanocrystalline Cr-containing Vitroperm-type alloys. J. Magn. Magn. Mater. 409, 56-61 (2016).

21. Chaudhary, V. \& Ramanujan, R.V. Magnetocaloric Properties of Fe-Ni-Cr Nanoparticles for Active Cooling. Sci. Rep. 6, 35156 (2016).

22. Chaudhary, V., Chaturvedi, A., Sridhar, I. \& Ramanujan, R. V. Fe\&amp;\#x2013;Ni\&amp;\#x2013;Mn Nanoparticles for Magnetic Cooling Near Room Temperature. IEEE Magn. Lett. 5, 1-4 (2014).

23. Chaudhary, V. \& Ramanujan, R.V. Magnetic and structural properties of high relative cooling power (Fe $70 \mathrm{Ni} 30$ ) $92 \mathrm{Mn} 8$ magnetocaloric nanoparticles. J. Phys. D. Appl. Phys. 48, 305003 (2015).

24. Rao, A. S. Alnico permanent magnets an overview. in Proceedings of Electrical/Electronics Insulation Conference 373-383 (IEEE, 1993). doi:10.1109/EEIC.1993.631186

25. McCaig, M. Recent Developments in Permanent Magnetism. J. Appl. Phys. 35, 958-965 (1964).

26. Allen, R.I. \& Constant, F.W. The Absolute Saturation of Cubic Cobalt. Phys. Rev. 44, 228233 (1933). 
27. Niu, C. et al. Spin-driven ordering of $\mathrm{Cr}$ in the equiatomic high entropy alloy NiFeCrCo. Appl. Phys. Lett. 106, 161906 (2015).

28. Yu, P.F. et al. The high-entropy alloys with high hardness and soft magnetic property prepared by mechanical alloying and high-pressure sintering. Intermetallics 70, 82-87 (2016).

29. Chaudhary, V. \& Ramanujan, R.V. High Relative Cooling Power in a Multiphase Magnetocaloric FeNiB Alloy. IEEE Magn. Lett. 6, 1-4 (2015).

30. Lucas, M.S. et al. Thermomagnetic analysis of FeCoCr x Ni alloys: Magnetic entropy of high-entropy alloys. J. Appl. Phys. 113, 17 A923 (2013). 


\section{CHAPTER 6}

\section{CONCLUDING REMARKS}

This thesis demonstrates several successful examples of how laser additive manufacturing, LENS ${ }^{\mathrm{TM}}$ specifically, can produce widely used binary and ternary soft magnetic materials (Fe-30at\%Ni and $\mathrm{Ni}-\mathrm{Fe}-\mathrm{Mo} / \mathrm{V})$, as well as a complex compositionally graded $\mathrm{AlCox}_{\mathrm{C}} \mathrm{Cr}_{1-}$ xFeNi system for rapid analysis.

For the Fe-30at\%Ni system, the variably processed samples indicated a shift in phase stability with respect to changes in laser power and laser travel speed, which was reflected in the magnetic measurements. The bcc dominated microstructures generated using fast travel speeds (20IPM) demonstrated magnetizations up to $40-50 \%$ higher than the $f c c$-dominated microstructures that were generated using slow travel speed (5IPM). While these results indicate the ability to somewhat create a gradation of magnetic properties by on-the-fly changing of processing parameters, this complete flip in phase stability presents a unique problem in additive manufacturing. Additive manufacturing, generally speaking, is a nonequilibrium processing method. Rapid heating and cooling can easily generate metastable phases and enormous internal stresses. In the case of Fe-30at\% $\mathrm{Ni}$, internal stresses during the process potentially aid in the martensitic $f c c-b c c$ transformation, which is evidenced by the fact that the reported martensitic start temperature for this alloy is approximately $-50^{\circ} \mathrm{C}$, and the lath-like morphology of the bcc phase with a Nishayama-Wasserman orientation relationship with the $f c c$ matrix. Given that this alloy is similar to heavily austenite-stabilized steels, this problem of phase transformations during the additive manufacturing process is also an interesting steels problem. 
For the Ni-Fe-Mo and Ni-Fe-V permalloys, only one set of processing parameters was used. In both cases, the microstructures and x-ray diffraction results show single phase fcc. The saturation magnetizations for these two systems are also very similar to the traditionally manufactured counterparts. The coercivities, however, are significantly higher than normal permalloys, and are attributed to a high degree of microstructural defects (e.g., pores and stress fields) that interrupt the nanoscopic magnetic domain structure in these alloys.

Finally, the graded $\mathrm{AlCox}_{\mathrm{C}} \mathrm{r}_{1-\mathrm{xFeNi}} \mathrm{Nomplex}$ concentrated (high entropy) alloy was deposited for at least two reasons: To establish LENS ${ }^{\mathrm{TM}}$ additive manufacturing as a viable scientific method to rapidly generate novel alloy compositions for study; and to show that creating a compositional gradation is possible using the LENS ${ }^{\mathrm{TM}}$ process. For this system, at $\mathrm{x}=1$ (no chromium), the saturation magnetization is the highest, which is expected due to the magnetic and antiferromagnetic natures of cobalt and chromium, respectively. The coercivities, in between, however, are curious, as coercivity is largest at $x=0.4$. This rise and fall of coercivity is attributed to an ultra-fine spinodal decomposition that forms in these compositions, disrupting the magnetic domains.

Significant work remains for the additive manufacturing of functional materials, especially if implementation of new magnetic materials and geometries in industrial applications is expected. Furthermore, LENS $^{\text {TM }}$ additive manufacturing presents unique benefits with the ability to compositionally grade parts using elementally blended powders, create unique geometries, and now, change phase stability via changes in processing parameters. 
Further studies will focus on the martensitic $f c c-b c c$ transformation in the Fe-30at\%Ni during processing. This will be a fundamental phase transformations study, and the results can be applied to heavily austenite stabilized steels.

Overall, this work shows that additive manufacturing is a viable technique for manufacturing magnetic materials. LENS ${ }^{\mathrm{TM}}$ can also be used for the rapid analysis of novel magnetic materials, which can be very useful for the replacement of rare-earth based magnets. Furthermore, additive manufacturing allows for the production of complex shapes. This, coupled with compositional gradation of magnetic alloys, can open up novel processing routes for unique shaped parts in a variety of electronics systems.

\section{Future Work}

There is still significant follow-up work to be done on the Fe-30at\%Ni, Ni-Fe-Mo/V permalloys, and $\mathrm{AlCo}_{x} \mathrm{Cr}_{1-\mathrm{x}} \mathrm{FeNi}$ magnetic systems. In order to establish the nature of the fcc to bcc transformation in Fe-30at\%Ni as a stress-induced or stress-assisted martensitic transformation, synchrotron x-ray diffraction studies were performed, but need further analysis. Using x-ray diffraction and analyzing the resultant two-dimensional Debye-Scherrer rings, residual stresses can be analyzed. If the transformation is indeed a product of stress in the microstructure, the $b c c$ phase should have lower residual stress than the parent $f c c$ columnar grains. Furthermore, determining the exact nature of the fine, homogeneously distributed particles is also important, as the ordered structure with the measured composition of $99 \% \mathrm{Fe}$ and $1 \% \mathrm{Ni}$ is an oddity. 
For the Ni-Fe-Mo and Ni-Fe-V permalloys, atom probe tomography needs to be used to determine if there is any sort of phase separation or spinodal decomposition due to LENS ${ }^{\mathrm{TM}}$ processing. The coercivities of both alloys are 4 orders of magnitude greater than what is commercially available, and a very fine spinodal decomposition could be a cause for it. Furthermore, the small black particles that are homogeneously distributed in the alloy should also be analyzed in TEM in order to determine their exact nature and relationship, if any, to the matrix and magnetic properties of the alloys.

For the $\mathrm{AlCO}_{x} \mathrm{Cr}_{1-\mathrm{x}} \mathrm{FeNi}$ complex concentrated alloy, further microstructural characterization is necessary to determine the exact cause of the heightened coercivity at the $\mathrm{x}=0.4$ composition. Antiphase boundaries may be present in the $\mathrm{B} 2$ matrix that disrupt the domain structure of the material, generating the large coercivities. Further TEM studies are necessary on both the as-deposited and solutionized/homogenized samples. 